\title{
PSS Strategic Alignment: Linking Service Transition Strategy with PSS Business Model
}

\author{
Mar'atus Sholihah *, Tatsuru Maezono, Yuya Mitake and Yoshiki Shimomura \\ Department of System Design, Tokyo Metropolitan University, Tokyo 191-0065, Japan; \\ maezono-tatsuru@ed.tmu.ac.jp (T.M.); mitake-yuya@ed.tmu.ac.jp (Y.M.); yoshiki-shimomura@tmu.ac.jp (Y.S.) \\ * Correspondence: sholihah-mar'atus@ed.tmu.ac.jp
}

Received: 14 October 2019; Accepted: 4 November 2019; Published: 7 November 2019

\begin{abstract}
One of the most promising business models towards economic circularity is product-service system (PSS). Despite its great potential benefits, shifting the traditional business model of a manufacturer into PSS business model commonly refers to service transition and triggers inconsistencies between strategic direction and organization arrangement at an operational level. The absence of alignment between the service transition strategy and the PSS business model is greatly emphasized as a crucial enabler, risk factor and key success factor of the service transition. However, limited academic works have concretely contributed to the strategic alignment. Through a systematic literature review, this paper proposes a PSS business alignment that enables the manufacturer to identify the strategic objective of its service transition strategy and align it with PSS business model. The theoretical version of the proposed framework is redefined and redeveloped through two cycles of action research involving 11 Japanese companies.
\end{abstract}

Keywords: strategic alignment; service transition; product-service system; strategy; strategic objective; strategy map; business model

\section{Introduction}

Product-service system (PSS) is a system of products, services, supporting networks, and infrastructure which is simultaneously designed to be competitive, satisfy customer's need, and carry a lower environmental impact compared to the traditional business model [1]. Under the PSS concept, service is no longer regarded as an "add-on" for the physical product, but more as an inseparable component for an integrated offering [2]. A PSS company earns revenue for the provided service. Any physical products and consumables used to provide the service become cost factors. The incentive is obtained by prolonging the service life of products (intensive use with cost- and material-efficiency). These elements concurrently lead to a minimization of material flows and maximization of customer satisfaction [3]. PSS is one of the most effective value propositions of a circular economy which enables the shift towards a resource-efficient and resource-creation revolution [3-8]. Hence, PSS is believed to be a prominent way to realize a more circular economy in micro-level operation [9].

Despite its great potential to achieve economic circularity, shifting the traditional business model of a manufacturer into the PSS business model commonly refers to a service transition $[10,11]$ and generates numerous challenges, particularly from an organizational transition perspective [12]. The service transition triggers inconsistencies between strategic direction and organization arrangement at an operational level [10,13-15]. These inconsistencies potentially hinder the benefits of PSS and even lead to a service paradox [16]. The company's product-dominant logic, organizational structure and employee ability centered on producing and delivering physical products represent examples of inconsistencies between organization arrangement with service transition intention [17]. 
The absence of common mindsets, understanding, and cooperation within the company, which is known as strategic misalignment, positively decelerates the transition towards PSS [17]. Therefore, "strategic alignment" has been underlined as a crucial challenge as well as a requirement in the service transition $[13,15]$. Strategic alignment is defined as the appropriateness of various elements to one another [18]. It happens when the company logic set (strategy and business model) conveys a close similarity to each other [18-21]. In this sense, the service transition intention needs to be clearly reflected in the company's strategy and mirrored in the changes throughout the business model [16]. The success of a company in service transition lays in its business model which requires to be redesigned to strategically align with the company's objective to provide PSS [22]. Meaning that, focusing on the business model development per se is not sufficient, further alignment needs to be achieved to create and capture new value [23].

Despite numerous research works in PSS, the current literature has greatly contributed to the development of the PSS business model, however, the requirement alignment between strategy and business model is occasionally neglected [24]. The notion of alignment between the two concepts has not yet been fully explored both in academic and real practice. Several academic works in the PSS business model have emphasized the importance of strategic alignment between service transition strategy and PSS structural elements [16,23,25-27]. However, a comprehensive framework that concretely supports the intention to affiliate the company's strategic direction with the business model remains unavailable [28-30]. While inadequate alignment between strategic and operational level prevents service innovation and is suspected as the rationale behind many unsuccessful PSS initiatives [25,31].

This present paper intends to fill in this research gap by answering the following research question: how is strategic alignment of a company in service transition towards PSS achieved? This paper, therefore, proposes a PSS strategic alignment framework as a means to facilitate the strategic alignment in service transition. To achieve this objective, first, a literature review on the strategic management field is conducted to acquire an adequate foundation of the strategic alignment concept and pertinent components necessary to be linked to realize the alignment. Then, PSS literature is systematically reviewed to scrutinize and comprehend the current body of knowledge on discussion, framework or proposed method of strategic alignment for PSS. Based on this result, a theoretical version of PSS strategic alignment is proposed. The first version of the proposal is then applied in action research. The action research aims to facilitate the further development of the theoretical version of PSS strategic alignment. It is based on a real application by practitioners from Japanese companies that are interested and in the process of service transition. As a consequence, the practical experience affords an opportunity to modify the proposal.

The remainder of this paper is structured as follows. Section 2 presents the research method used to conduct the research. Section 3 presents the result of the literature review on the strategic management area to reveal the concept of strategic alignment. Section 4 provides the theoretical development of the proposed PSS strategic alignment. The empirical development of the proposed framework is shown in Section 5. Finally, Section 6 concludes the paper and presents future work.

\section{Research Method}

The present paper is built through three sequential research stages as shown in Figure 1. The detailed description of each stage is presented in the following sub-sections. 


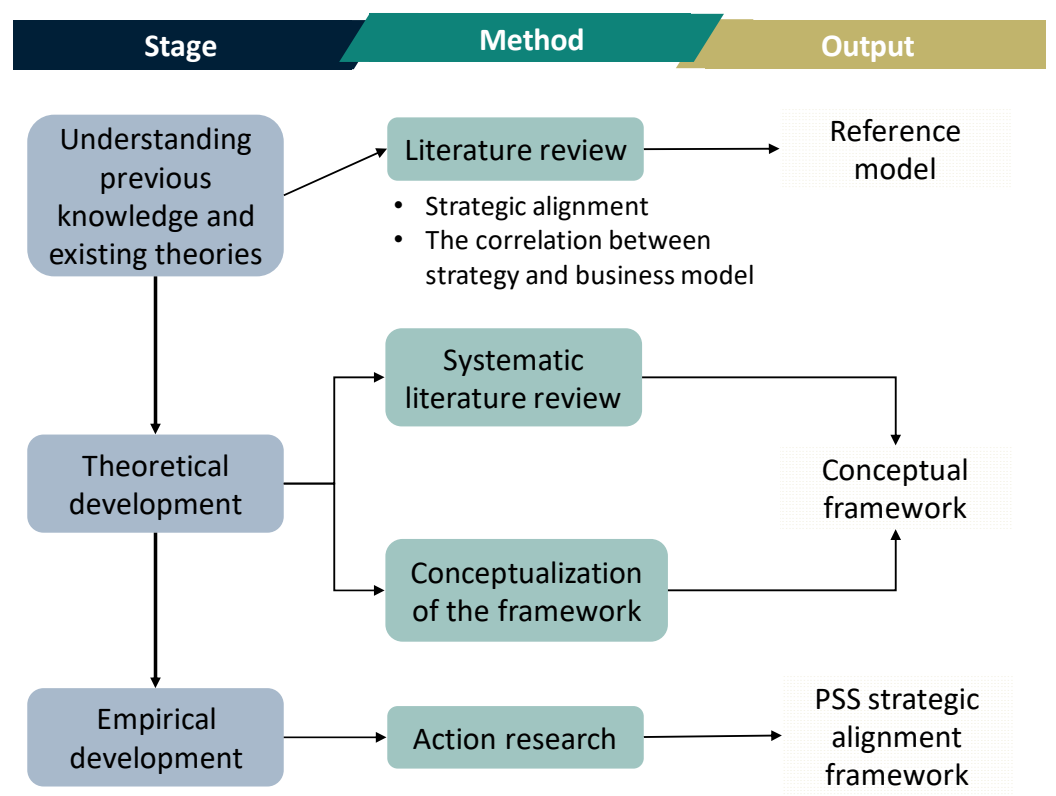

Figure 1. Research method.

\subsection{Stage 1 Understanding Previous Knowledge and Existing Theories}

Initially, a literature review was conducted to analyze and comprehend previous knowledge and existing theories on the strategic management area. Specifically, this stage aims to acquire the knowledge on the strategic alignment concept. The review of strategic management literature also intends to comprehend knowledge of strategic direction, business model, and the relation of the two concepts to construct a strategic alignment. This stage is devoted to providing a theoretical basis for undertaking the research and for the development of PSS strategic alignment. The output of this phase is a reference model of the strategy-business model relation in which strategic alignment occurs. The reference model is needed to guide the development of PSS strategic alignment, as the concept of strategic alignment is initially established in the strategic management area which has been broadly adopted in the wider research fields including PSS. The review result is presented in Section 3.

\subsection{Stage 2 Theoretical Development of PSS Strategic Alignment Framework}

The second stage of the research is the theoretical development of PSS strategic alignment framework. This stage aims to establish the theoretical version of the proposed framework based on a systematic literature review [32]. Different from a general literature review, a systematic literature review utilizes a scientific, transparent, and replicable process [33]. Therefore, the drawback of review bias can be reduced. Furthermore, robust and reliable results from which to draw conclusions are more attainable [32]. A systematic review of the PSS literature, particularly in research related to strategic alignment, affords an opportunity to advance the understanding of relevancy, discussion, and concrete endeavors of strategic alignment during the service transition.

The systematic literature search was conducted on journal articles utilizing the Scopus database. Albeit as a single database, the Scopus database covers a wide subject and journal range and has been considered as the best tool for electronic literature search [34]. It includes considerable numbers of major and minor publishers along with covering multi-disciplinary research fields. It certainly is beneficial in obtaining a large amount of research on PSS [35]. The strategy to use the Scopus database is consistent with the recent reviews in PSS research field [3,26,35].

The potential articles were obtained by using keywords search. A predefined combination of keywords was used to find the potential articles. The keywords were derived from the previous literature reviews on PSS [3,26,35]. The literature search was executed using the combination of the following keywords: "alignment", "strategic alignment", "organization alignment", "business 
alignment" and keywords denoting company transition to PSS which are "product-service system", "PSS", "industrial product-service systems", "integrated solution", "servitization", "service transition", "servicification", "service infusion", "integrated product-service offering". This search resulted in 389 potentially relevant articles. The citation information, abstract and authors' keywords of those articles were exported using Scopus CSV export menu. It was changed into an Excel spreadsheet for further analysis.

The collected potential articles from the keywords search were refined using three screening processes based on the works of [26,35], as described as follows and illustrated in Figure 2.

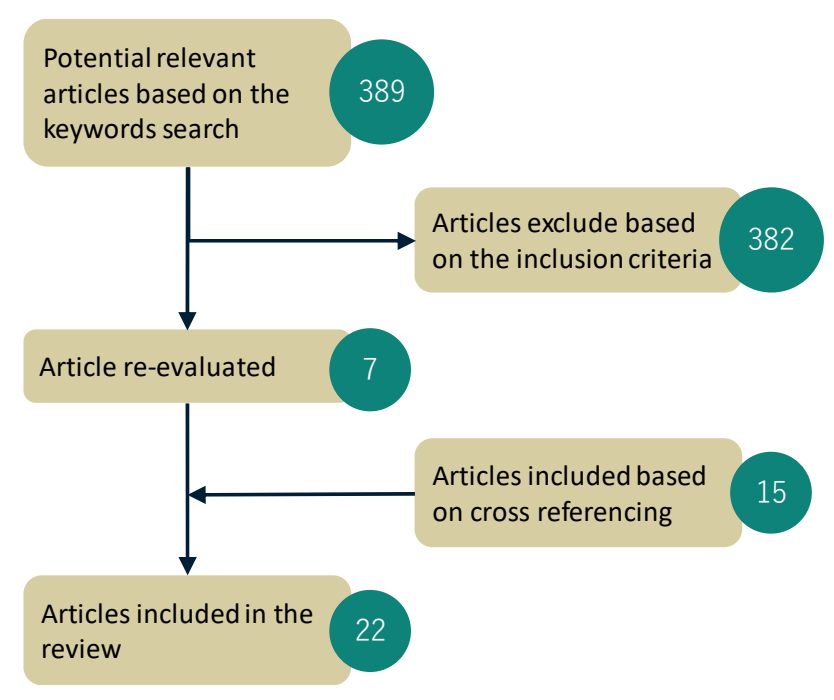

Figure 2. Systematic literature review flow diagram.

\subsubsection{Practical Screening}

To assure that research articles used in the review were qualified ones, first practical screening criteria were set comprising document type and language. Articles published in peer-reviewed journals were selected according to the desired document type. Therefore, book chapters, books, editorials, and conference papers were omitted. Non-English-written articles were also excluded. Some previous systematic literature reviews on PSS use additional practical screening, e.g., journal ranking and number of citations [3], however the present paper does not use those additional criteria due to the fact that alignment in service transition is an emerging topic in PSS research. The research works under this topic may not be published in highly ranked journals or may not have been extensively cited. Based on this practical screening, 270 potential articles were retained in the database.

\subsubsection{Theoretical Screening}

Since the goal of the systematic literature review is to focus on strategic alignment in PSS, only conceptual or empirical articles which discussed relevancy or emphasized the role of strategic alignment in PSS, as well as those that proposed framework as a concrete attempt to achieve the alignment, were included. The specific criteria to include the relevant articles are as follows:

- Explicitly discuss alignment within a PSS company. Articles which conceptually or empirically discuss strategic alignment within the company during the service transition remained to be included.

- Implicitly discuss alignment within a PSS company. Articles which implicitly or indirectly provide a conceptual or empirical reference to organizational alignment, for instance defining the potential misalignment which hinders the transition to be a PSS company, or articles which emphasize the importance of unified desired stage of transition to be achieved were included. 
This theoretical screening was conducted by analyzing the exported article information in step 1 . The original procedure suggested from [35] is that screening is conducted using one iteration, merely by reading titles and abstracts of the articles. However, in this research the theoretical screening was carried out in two iterative steps. First, two separate researchers read the titles and keywords of the articles. Each article was labeled with 'pass' or 'not pass' for the next screening. Then, the results from both researchers' beliefs were reviewed. In a case when there were different labels, both researchers carefully read the abstract and decided to include or not include the article in the database. The second iterative was conducted by reviewing the abstracts. During the consolidation in case the review results were different, both researchers scanned the entire articles to include or not include the articles. The main reason to divide the theoretical screening into a two-iterative-step process was to afford an opportunity to thoroughly evaluate the articles by carefully and deeply reviewing the articles' titles, keywords, and abstracts in step-by-step manner. This time-consuming and tough process resulted in more legitimate decisions to include or not include the articles. The first iteration excluded 228 irrelevant articles and the second iteration excluded 35 articles, so only 7 articles remained to be further analyzed. The small number of remaining articles directly shows that the topic of strategic alignment in PSS literature is relatively new and emerging. Not so many research studies have been focused on or published on this related topic.

\subsubsection{Final Screening and Cross Reference Analysis}

The seven articles included from the previous screening processes were downloaded and read in detail. Each article's references became an additional literature source to collect the relevant studies contributing to the focus topic in this research. In particular, attention was given to the relevant contributions on elements corresponding to strategic alignment, which may not make any specific reference to the strategic alignment approach. For example, these could be articles addressing service strategy model which also emphasize the connection between strategic level and operational level within the company [35-37]. Moreover, the articles which have specifically adopted a business model perspective to discuss the service transition were also included, as a business model is a reflection of a company's changes (structure, culture, and competencies) affected by the shift towards delivering PSS [26]. Hence, the business model plays an important role in sensing the alignment or misalignment of day-to-day company operation with strategic direction. This cross-reference analysis led to an additional 15 articles. Hence, in total there were 22 articles as the basis of the systematic literature review in this research.

In the following process, an open coding content analysis technique was used [35]. Heading and note were given in the text of the articles, corresponding to the research focus. To assist in analyzing and synthesizing the theoretical knowledge from the selected articles, predefined sub-research focuses were generated, as follows:

- Clarify the relevance and importance of strategic alignment in service transition;

- Systematize the strategic alignment framework proposed in the literature.

Subsequently, all headings were collected and categorized based on these sub-research focuses. In addition, the reference model identified in stage one affords navigation to systematize the strategic alignment framework for a PSS company, as available in the literature.

The accumulated knowledge from the systematic literature review process (as shown in Sections 4.1 and 4.2) was used to develop the conceptual framework of PSS strategic alignment. In order to facilitate the application of the proposed framework, an application method was created as well. Finally, those aspects were consolidated as the theoretical version of PSS strategic alignment (presented in Section 4.3). 


\subsection{Stage 3 Empirical Development of PSS Strategic Alignment Framework}

The last research stage is the empirical development of PSS strategic alignment. An action research approach was selected to further develop the current version of PSS strategic alignment. Action research is an iterative-reflective design process, originally applied to social problem-solving, which includes an implementation of action to study its consequences [38]. It is a form of applied research which combines scientific methods with practical knowledge. Action research utilizes a series of steps where each step has a circle of situation analysis, planning, action, and evaluation in which the consequence of the action is evaluated. This iterative and reflective process intends to obtain a particular goal by changing the situation and improving the action. By observing an active engagement and collaboration among researchers and practitioners towards a pre-defined social problem, a theory can emerge which would be a source of empirical development of the applied method or approach [39].

The action research method used in this research was inspired by the framework of [38]. In particular, action research was conducted in two cycles. In the first cycle, the theoretical version of PSS strategic alignment was presented and then applied in a workshop with multinational researchers in an innovative design laboratory in Japan. This laboratory manages a service design school (http://www.comp.tmu.ac.jp/smmlab/research/d-cocoon_e.html) which promotes a service engineering approach in assisting value creation through corporate collaboration and practical education for human resources who contribute to future value creation in Japanese companies. The service design school fundamentally acts as a business academia collaboration incubator, however, it also actively promotes intensive research and application in the PSS research area, particularly in assisting the business partners which are interested or on the journey towards PSS. The participant of the first action research cycle was 12 researchers, including PhD candidates and final master's students who have been actively involved in the service design school workshop with business partners. They were selected because of their understanding of PSS research and their practical experience in collaboration with PSS companies in Japan. Hence, the participants were expected to give insightful feedback for the refinement of the proposed framework and supporting method, before it was used in the second cycle of the action research. The result of the action research cycle 1 is presented in Section 5.1.

The second cycle of action research was conducted in a series of workshops with practitioners from 11 Japanese companies in collaboration with the service design school for one month. Originally, the participants of the workshops were 30 people from 13 Japanese companies. However, only 13 people from 11 companies were willing to give feedback on this action research. The represented companies not only included to multinational manufacturing companies, such as an auto parts manufacturer, an office machinery manufacturer, and an electronics manufacturer, but also included some service companies who currently provide integrated product and service such as a communication infrastructure company, as well as an information technology and communication systems companies. The participants' positions varied from the middle to the middle-high level of management in business innovation divisions, product and service departments or system engineering departments. The detailed company names and those of the participants are kept confidential. The result of the action research cycle 2 is presented in Section 5.2.

To evaluate the action research, the relevant data comprising the recordings of the workshops and the feedback questionnaires were collected. The feedback questionnaires were divided into two types. For action research cycle 1, the feedback questionnaire consists of open-ended questions which aimed to collect information of: (1) the ambiguous parts of the proposed framework and the supporting method; and (2) the improvement suggestions. These types of questions were seen as suitable to be addressed by the fellow researchers who also work in the PSS research area. Whereas, for the research action cycle 2, the feedback questionnaire was developed not only in the form of open-ended questions but also based on the method evaluation model [40]. This evaluation method is based on a notion that a proposed framework is considered to be success if it satisfies two dimensions of "success". The first dimension is actual efficacy, a condition where the proposed framework improves the performance of the task. Whereas, the second dimension of success is the degree of intention to use, 
i.e., that the proposed framework is highly desirable to be implemented in real practice. The second dimension highlights one of the fundamental promises of research development where the benefit of the proposed framework can be obtained if and only if it is genuinely applied in the practice. In detail, the two evaluation dimensions are divided into five dependent (outcome) variables (denoted as " $\mathrm{D}$ ") as follows:

- D1-Actual Efficiency: the effort required to apply the framework

- D2-Actual Effectiveness: the degree to which the framework achieves its objectives

- D3-Perceived Ease of Use: to what extent a person believes that adopting the proposed framework would be free of effort

- D4-Perceived Usefulness: the degree to which a person believes that the proposed framework would be effective to achieve its intended objectives

- D5-Intention to Use: to what extent a person intends to use the proposed framework.

There is a cause effect relation among these dimensions. Actual efficacy (D1 and D2) determines perceived efficacy (D3 and D4). Then, perceived efficacy defines intention to use (D5) and finally, it triggers the actual usage (the extent to which a method is used in practice). D1 and D2 were reflected in two open-ended questions (Questions 17 and 18 in the questionnaire), while D2-D5 were indicated in 16 questions (Questions 1-16) using a 5-point Likert scale. The Likert scale questions were designed to include some negative statements (intentionally negated before), thus the response to these questions would be negated in data analysis to ensure the consistency. This design was adopted to prevent respondents from manipulating question items [41]. In addition, the questions were arranged in a random order to reduce the possibility of respondents giving monotonous responses to the questions [41]. Besides the 18 questions, an open-ended question was added to record the improvement feedback suggested by the participants. The result of these two cycles of action research led to the further empirical development of the proposed PSS strategic alignment framework, as discussed in Section 5.3.

\section{The Concept of Strategic Alignment: From Strategy to Business Model}

Strategic management is the art and science of formulating, implementing, and evaluating cross-functional decisions that enable an organization to achieve its objectives [42]. The concept of alignment, commonly referred to as strategic alignment, is a mature topic in the strategic management field. The concept was firstly initiated by the McKinsey 7-S framework [43]. The framework reveals seven internal elements of an organization, comprising strategy, structure, system, shared value, skill, staff, and style, which need to be well aligned and mutually reinforced in the pursuit of organization performance [43,44]. It was further conceptualized by [45] as a desirable "fit" stage of company strategic management. The fit between strategy and internal arrangement significantly leads to the intended organization performance, therefore one of the primary tasks of senior managers is to manage the consistency among multilevel elements inside the organization [18].

Initially, the achievement of alignment to be achieved between strategy and the internal arrangement of the organization [19], namely internal alignment, was urgently emphasized. However, this concept evolved, yielding the expansion of its scope into the company's business environment, known as external alignment. External alignment is defined as a dynamic effort to link internal elements of the organization and its environment, and then adjusting the organizations' internal resources to support this attempt [46]. In this sense, the principle of alignment essentially lies in the degree of consistency that exists between competitive situation, strategy, organization structure, culture, and leadership style [18].

The necessity and importance of alignment have been broadened to many different perspectives inside and outside the organization, for instance, the perspective of the need for leveraging IT strategy with the company's business strategy [47]. The work of [48] focused on alignment in a different angle of internal strategy hierarchy, i.e., corporate, business and functional levels. Meanwhile, the 
research of [49] specified strategic alignment as achieving the company's goal by closely managing the company's value chain, which links its goal to the company's business strategy, capability, resource architecture, and finally management system, including the related aspects of infrastructure, tactics, and operation.

Although there are many perspectives of alignment, strategic alignment means the appropriateness of the various elements within the organization to one another $[18,21]$ which triggers and enables generating positive organizational performance. This research specifically gives attention to the fit and consistency between strategy and business model as the new structural arrangement of the organization, since the relation between strategy and business model has been well validated and promoted as the crucial call for alignment in the organization [21].

Both the strategy and the business model are well-known concepts in strategic management literature. The strategy has a vigorous root in the military and has been widely expanded in policy and managerial sciences since the early 1940s [50,51]. The business model has gained prominence and has seen widespread use both among the community of practice and academicians over the past two decades. However, the two terms have been commonly confused one another [52]. Specifically, the term business model is regarded as an extremely important concept, but there is no consensus of its meaning [52]. The term has frequently been misused with inconsistent definitions and vague boundaries [53]. Thenceforth, it is crucial to clarify the concept, boundary, and relation between strategy and business model in order to obtain a robust and reliable theoretical foundation of strategic alignment between the two elements.

Despite the fact that strategy and business model are related, they are different concepts in which a business model is the immediate reflection of the selected strategy, but is not itself a strategy [52,54]. A strategy is a company's contingency plan of actions, the choice of what business model will be used to run the business [54]. It is an integrated and coordinated set of actions and commitments devised to utilize organization competencies and acquire a competitive advantage $[55,56]$. It includes designing a business model and the possibility to redesign it to direct the organization to achieve the intended goals. Meanwhile the business model refers to the "logic" of the company in how it operates and creates value for stakeholders based on a particular combination of resources [52,54]. A strategy and a business model are distinct at least in two ways: (1) the business model is the reflection of the strategy, while the strategy itself plans the development of capabilities which enable the change of the current business model in the future; (2) strategy is the company's plan to achieve a particular goal in the future, while the business model is the representation of the "logic" of the company at a specific time [52,54]. Table 1 summarizes other distinctions between the two concepts.

Table 1. Distinctions between the concepts of strategy and business model.

\begin{tabular}{ccc}
\hline Distinctness & Strategy & Business Model \\
\hline Definition & $\begin{array}{c}\text { An integrated and coordinated set } \\
\text { of actions and commitments } \\
\text { devised to utilize organization } \\
\text { competencies and acquire a } \\
\text { competitive advantage [55,56] }\end{array}$ & $\begin{array}{c}\text { The logic of the company in how it } \\
\text { operates and creates value for } \\
\text { stakeholder based on a particular } \\
\text { combination of resources time } \\
{[52,54]}\end{array}$ \\
\hline The main question to be addressed & $\begin{array}{c}\text { What do we want to become and } \\
\text { how do we achieve it? [39] }\end{array}$ & $\begin{array}{c}\text { How do we run our business? } \\
\text { [52,54] }\end{array}$ \\
\hline Component of the broad concept & $\begin{array}{c}\text { Goal, objective, action plan, policy } \\
\text { [51] }\end{array}$ & $\begin{array}{c}\text { Value proposition, finances, } \\
\text { revenue model, resources, service } \\
\text { provision (key activities), } \\
\text { customer, and network [26,57] }\end{array}$ \\
\hline Time horizon perspective & Long-term perspective [52] & $\begin{array}{c}\text { Present and short-term } \\
\text { perspective [52] }\end{array}$ \\
\hline
\end{tabular}


In addition, as an attempt to clearly separate and relate the strategy and business model, integrative frameworks of strategy business model relation were proposed by [52,54]. These frameworks define and illustrate the difference between strategy and business model, and likewise the relation which links them. The two frameworks share the same notion yet use different approaches to illustrate the strategy business model relation. The framework of [52] visualized strategy and business models as independent elements that are connected in the way of strategy creating the development of capabilities enabling the transformation of the business model in the future. The use of gear shapes and arrows in this framework emphasized that strategic alignment needs to continuously endeavor because the dynamic nature of a competitive situation requires continuous formulation and execution of strategy. This fact makes the strategic fit a moving target [18].

The framework of [54] demonstrated a more direct and stronger connection between strategy and business model. In this framework, the strategy is not merely a selection of possible business models, but a contingent plan of how the business model should be configured, considering the likelihood which may occur. In this framework, the business model is the reflection of the realized strategy [54]. Both frameworks were used as reference models in this research to further develop the strategic alignment for a PSS company. However, this research does not further explore dynamic capabilities and tactics as illustrated in the frameworks of [52] and [54], since the present paper aims to contribute to the intention to achieve strategic alignment between strategy and business model.

\section{Theoretical Development of PSS Strategic Alignment}

\subsection{The Relevance and Importance of Strategic Alignment in Service Transition}

The researchers in PSS originally share a common ground of service transition being a movement of a traditional manufacturer to provide more values to its core offering by adding services. There are two main streams of how the movement can be undertaken. The first stream believes in the notion that transition happens in the incremental product-to-service continuum [14,58-60], where the manufacturer gradually adds the service aspect in their offering and the organizational change is adjusted to support the attempt [58]. On the contrary, service transition is also regarded as a continuous process which is intuitive and emergent in nature, instead of a structured process following a specific continuum $[36,61]$. The journeys of the manufacturers towards service transition can be logically divergent among each other considering each company's specific context [62]. In spite of different perspectives existing as to how the transition emerges, there is a broad consensus among PSS researchers that the adaptation of strategic management theories is beneficial to foster the maturity of the PSS research field [11,36,37,63-65]. This paper shares the same belief on that premise and attempts to further contribute to the maturity of the PSS research field by exploring strategic alignment indispensable for a PSS company.

As reflected in the number of articles in PSS literature (Section 2.2) which specifically devote their focus to strategic alignment, the attention that has been paid to this topic remains limited. However, the identified articles greatly emphasized the relevance and importance of alignment for service transition $[13,17,24,31,66-69]$. Consistency between the change process, the development of service capabilities, and the multi-level cooperative relationship among them plays an important role as an enabler for the transition towards PSS [67]. Therefore, the company needs to ensure its several internal elements including top management commitment, risk management, service design capabilities, supplier management, and service culture readiness are concurrently present and harmoniously aligned so the transition from product to service can be established [13]. Moreover, research done by [66] proposed a sequential step of strategy development for the transition from basic product to service-based solutions. This work highlights the alignment proposition to manage the service transition barrier [66] since misalignment between the top managerial intention to be a PSS company and the organizational intent to maintain the existing manufacturing business lead to the resistance to 
the service transition [17]. Thus, the presence of strategic alignment is an essential enabler to embark the transition into PSS.

The strategic alignment in service transition is also regarded as a risk factor. A profound analysis of the outcome-based service contracts revealed twenty-three risk factors under five dimensions, including misalignment. The inconsistency of six aspects in the outcome-based contracts between provider and customer was found as an important rationale behind commercial and operational risk [31]. In addition to these two perspectives, the most common belief regarding strategic alignment in service transition is its role as a key success factor $[13,68,69]$. The strategic alignment among the company's internal elements, as well as with its customer, affords a contingency to establish a more sustainable business model of integrated solutions [68]. If a company intends to develop more integrated offerings, the company needs to initially utilize its existing activity and resource base, then focus on aligning the value appropriation logic for the inter-firm alignment of its business model [69]. The strategic alignment is a key success factor to manage the challenges in service transition, specifically among four essential aspects: (1) the strategic orientation and the service portfolio; (2) the strategic orientation and the internal organization; (3) the internal dimensions and the service network; (4) the internal dimensions and the customer [13].

Table 2 summarizes the relevance and importance of strategic alignment in service transition identified from the systematic literature review. In general, inconsistencies between the organization-related elements happen due to transformation challenges [13]. The knowledge stock in the literature has emphasized the relevance and importance of strategic alignment for service transition. The following section presents the endeavors in the current PSS literature to achieve the strategic alignment in service transition.

Table 2. The relevance and importance of strategic alignment in product-service system (PSS) literature.

\begin{tabular}{cl}
\hline $\begin{array}{c}\text { Pivotal Role of Strategic } \\
\text { Alignment }\end{array}$ & \multicolumn{1}{c}{ Key References } \\
\hline \multirow{2}{*}{ Enabler } & $\begin{array}{l}\text { The alignment among change process, capability development, and cooperative } \\
\text { relationship enables PSS business model implementation [67] } \\
\text { Misalignment between top managerial and organizational intentions triggers } \\
\text { resistance to service transition [17] } \\
\text { The alignment proposition is needed to manage the transition barrier from basic } \\
\text { product to service-based solution [66] } \\
\text { The company needs to ensure several internal elements are concurrently present } \\
\text { and harmoniously aligned so that the transition from product to service can be } \\
\text { established [13] }\end{array}$ \\
\hline Risk factor & $\begin{array}{l}\text { Misalignment between provider and customer in the outcome-based contracts is } \\
\text { a risk factor for commercial and operational aspects [31] }\end{array}$ \\
& $\begin{array}{l}\text { Strategic alignment between a company's internal dimension and its customer } \\
\text { allows the development of more sustainable PSS business model [68] } \\
\text { The inter-firm alignment of a business model is a key for establishment of more } \\
\text { integrated offerings [24,69] } \\
\text { Feyr crucial aspects need to be well aligned in service transition, i.e., the strategic } \\
\text { orientation and the service portfolio; the strategic orientation and the internal } \\
\text { organization; the internal dimension and the service network; and the internal } \\
\text { dimension and the customer [13] }\end{array}$ \\
\hline
\end{tabular}

\subsection{Analysis of The Existing Endeavors for PSS Strategic Alignment}

Although the necessity of strategic alignment is occasionally neglected [24], some substantial studies have been carried out by PSS researchers. Several researchers provide conceptual frameworks either to advocate the understanding of the topic or to concretely facilitate the achievement of strategic alignment in the service transition. The understanding is built by the identification of the relevant dimension of strategic alignment and its associated elements. Following the original concept of strategic 
alignment in the strategic management area, researchers in PSS indicated two dimensions of strategic alignment, namely internal alignment $[15-17,22-27,35,37,67,70]$ and external alignment $[30,31,68,71]$. Not only treated as separate concepts, internal and external alignment were also underlined by several PSS researchers as an inseparable integration $[13,36,66,69,72]$. The result of the literature review in the strategic management area suggests that the element of organization necessary to be aligned is varied depending on the scope of analysis $[18,21]$. Table 3 summarizes the pertinent elements of strategic alignment in PSS literature based on the perspective of internal, external, as well as integrated internal and external dimensions.

Table 3. The dimension of strategic alignment in service transition found in the literature.

\begin{tabular}{|c|c|}
\hline The Dimension of Strategic Alignment & The Pertinent Elements of the Strategic Alignment \\
\hline $\begin{array}{c}\text { Internal Alignment } \\
{[15-17,22-27,35,37,67,70]}\end{array}$ & $\begin{array}{l}\text { Alignment in service business development, i.e., strategic } \\
\text { intension, business logic, value constellation [70] } \\
\text { Business model development and capabilities development [67] } \\
\text { Consistency among strategic logics [37] } \\
\text { Strategy and business model [15-17,22,23,25-27,35] } \\
\text { Strategy and company's resource [24] }\end{array}$ \\
\hline External Alignment $[30,31,68,71]$ & $\begin{array}{l}\text { Business model and environmental aspects (legal, technological } \\
\text { and economical) [71] } \\
\text { Internal dimension (PSS business model) and service network } \\
\text { (partner) [30] } \\
\text { Internal dimension and customer [68] } \\
\text { Five aspects of a PSS project including goal, vision, practice, } \\
\text { understanding, culture and bargaining power between PSS } \\
\text { company and customer [31] }\end{array}$ \\
\hline $\begin{array}{l}\text { Internal and External Alignment } \\
\qquad[13,36,66,69,72]\end{array}$ & $\begin{array}{l}\text { Internal alignment: strategy and organization structure; External } \\
\text { alignment: internal dimension and business partners [66] } \\
\text { Internal alignment: strategic orientation, service portfolio, and } \\
\text { organization arrangement; External alignment: internal } \\
\text { dimensions, service network, and customer [13,36] } \\
\text { Internal alignment: organization structure; External alignment: } \\
\text { internal element and network companies [69] } \\
\text { Internal element, intermediaries, and customer [72] }\end{array}$ \\
\hline
\end{tabular}

Internal alignment in PSS is seen as the extent to which the new service system "matches" with the company's profile, encompassing its managerial skills, competencies, and resources [24]. In current PSS literature, the pertinent element of internal alignment varies ranging from strategic intention, a company's resources, to its business model. However, the consistency between service transition strategy and the PSS business model is the most emphasized strategic alignment in PSS literature [15-17,22,23,25-27,35]. A conceptual framework of PSS strategy business model relation proposed by [35] highlighted the urgency of internal alignment in PSS. This study employed the reference model of [54] which was also adopted by this present paper. The study defined service transition strategy as the intention of a manufacturer to increase service-related offerings, which then translate into three possible business models, namely product-, use- and result-oriented PSS. The translation of strategy into the business model denotes the connection between the two concepts. Thus, the appropriateness between strategy and business model needs to be present.

On another hand, several researchers believe that the internal consistency within a company is required to be expanded into the external dimension $[30,31,68,71]$. Because the nature of PSS as a service ecosystem involves multiple stakeholders, the concept of external alignment arises in PSS. The harmony between the PSS company with several external elements is mentioned to contribute to the success of the system, particularly for the value co-creation process [68]. An empirical framework proposed by [68] emphasized the important role of strategic alignment to reinforce a longer relationship and deeper collaboration to co-evolve and co-create the value with the customer. The consistency between 
the two parties is needed to harmoniously connect their goals, resources, and capabilities. Under this concept, the main focus is given to the identification of external elements necessary to be connected to the PSS company, whereas the specific element from the internal dimension is rarely mentioned. The most acknowledged concept of external alignment is the consistency of the PSS company with its customer and business partner covering the aspects of goal, vision, practice, understanding, culture and bargaining power of the agreed service system $[30,31,68,71]$.

Different from the previous concepts, the last notion of strategic alignment in service transition is the integration of internal and external alignment. Research devoted to this concept regarded both alignments as an inseparable component. Hence, the endeavor to realize an alignment is given to internal and external dimensions of the service system. The most comprehensive study of internal and external dimensions of strategic alignment in PSS was presented by [13]. This study firstly identified challenges of service transition and then proposed a strategic alignment framework to overcome the challenges. The study emphasizes five internal and external elements necessary to be aligned in four alignment directions. To achieve the internal alignment, the company is firstly required to harmonize its strategic orientation, service portfolio, and organization arrangement. Then this internal dimension is further integrated with service network and customer as the external factors. Despite the fact that the study also proposes key actions to achieve alignment, the proposed key actions are conceptually based on limited practicability. The specific way to achieve alignment remains unavailable. This condition affords an opportunity for top management to identify misalignments yet performing corrective actions cannot be directly executed.

Furthermore, the work of [15] proposed a service strategy model recognizing that strategic alignment happens if the company internally shares a common language, mindset, and understanding of its commitment and effort in the transformation to be a PSS company, while at the same time closely engaging its service culture with customers and service partners. If the lower-level decision (operational) is carried out in a consistent fashion with the upper level (strategy), strategic alignment can be realized [48].

Based on the existing endeavors to achieve alignment in service transition, both internal and external dimensions of strategic alignment play a significant role. However, the consistency among internal elements of the organization, specifically between the service transition strategy and PSS business model, is highly emphasized in the literature. This is reflected by the number of research studies focusing on this dimension of alignment, as shown in Table 3. The consistency of the relationship between the company's strategic priority and its business model is an important determinant in service transition [24], as an enabler and a key success factor. The consistency of strategic direction (strategic level) with the company's business model (operational level) is pivotal since service transition is a top management issue with enormous strategic implications [73] including the commitment of the top management. Executive leadership and commitment are essential to translate the strategic direction into action in everyday business [13]. Insufficient commitment leads to inadequate investment (tangible and intangible resources) in business model innovation and operation. Hence, the present research focuses on the realization of strategic alignment in which consistency is intended to be present between company service transition strategy and its PSS business model.

The study of [35] provides fundamental insight into the present research. Not only does it provide an apparent relation between strategy and business model in PSS context, it also shares the same notion with reference model of [54] on how the relation of strategy and business model occurs. However, a concrete connection between them is required since it is essential to analyze the service transition strategy in detail and as a manageable action. The strategy of service transition demands to be reviewed as the context of transformation (the situation), the process of transformation (what changed) and content of transformation [63].

Responding to this requirement, the work of [37] proposed strategic objectives for service transition based on the framework of the strategy map of the balanced scorecard [74]. A term of "strategic objective" was adopted [74-77] in strategic management to denote the specific goal of a company in 
a short-term horizon as a derivation of a long-term strategy. However, the proposal was developed based on three case studies. The research project involved multiple well-established PSS companies in Europe who have successfully accomplished the service transition process. Hence, the identified strategic objective in this study is more as a set of best practices or references which concedes the possibility of incompatibility to each manufacturer's context. The work of [37] stretched the service transition strategy into a detailed action plan by employing a strategic management approach. It gives a pivotal foundation on this topic. Nevertheless, the process of how to define strategic objective based on company's context remains irresolvable. The context of transformation (the situation), the process of transformation (what changed), and the content of transformation are unique entities for each manufacturer [63].

This research aims to extend the research of [35] by further extending the detailed aspect of service transition strategy and then connecting it to the PSS business model to realize the strategic alignment. To structurally respond to "how is strategic alignment of a company in service transition towards PSS achieved?" the research question is deployed into two issues, as shown in Figure 3. The first issue is how the company formulates strategic objectives for service transition strategy which merit its context. The second issue is how to align the identified strategic objectives with the company's PSS business model to ensure the realization of strategic alignment. The alignment is indicated by the consistency of strategic objectives, as the reflection of service transition strategy, and the business model element. The intention to take the service path needs to be clearly mirrored in the changes in all structural elements of the business model [23].

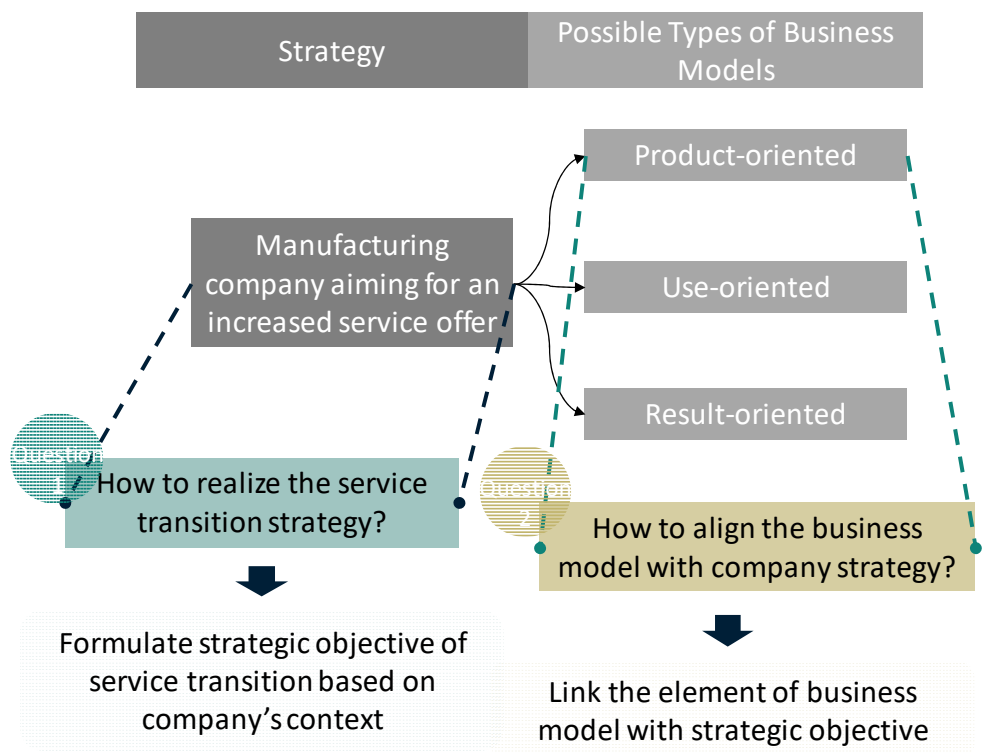

Figure 3. Deployment of the research question (elaboration based on $[35,54]$ ).

\subsection{The Proposed PSS Strategic Alignment}

The proposed framework is developed to respond to the aforementioned issues. The first issue is how to deploy the service transition strategy into more manageable targets. Here, strategy objective (SO) is used to represent a measurable step to achieve a strategy [77]. In perspective of time horizon, strategy is devoted to long-term planning, whereas an $\mathrm{SO}$ points out a particular objective targeted to be achieved in a relatively short period of time. Achieving SOs means realizing the long-term strategy. If this concept is applied in PSS, service transition strategy can be defined as "the intention of the manufacturer to increase service offer" [35]. Therefore, the way to increase service offering into manageable SOs is the first issue to be addressed.

There are several alternative procedures to identify an SO. An alternative procedure includes understanding the corporate mission and goals, analyzing the external and internal environment, 
and then formulating strategic objectives by using one or more possible alternatives that utilize the company's strengths, improve its weaknesses, take benefit of external opportunities and prevent external threats $[42,56]$. The study of [42] proposed a specific supporting tool for each step in SO formulation, including the quantitative strategic planning matrix (QSPM) designed to facilitate the decision-making process in choosing what SOs are intended to be implemented. Whereas, the study of [78] presented a simple yet practical method for identifying an SO by adopting the strategy map concept. In this method, the identification of the $\mathrm{SO}$ is based and grouped on the four perspectives of the strategy map. The uniqueness of this proposed method lies in the modification of the strengths, weaknesses, opportunities and threats (SWOT) matrix to identify the alternatives of SO. It reinforces the effort to focus on current strengths, adjust internal weaknesses, take benefit of opportunities and at the same time resist external threats.

The strategy map is a visualization of the organization's strategy on a single diagram which presents the cause-and-effect relation among SOs [74]. The SOs are classified into four perspectives of the organization, comprising financial, customers, the internal business process, as well as the learning and growth perspective. It supports comprehensive dissemination of the strategy to all stakeholders in a simple way [76]. A strategy map supports the realization of strategic alignment through the promotion of a common mind set and understanding of the company's goal. More importantly it assists the awareness that the success of company rests on the effort of each entity of the company. This concept has gained enormous attention with high application in real businesses, including in PSS research through the work of [37]. Accordingly, the method of [78] is a compatible answer to identify SOs for the service transition strategy. It is highly applicable yet has scientific rigor based on the framework of the strategy map which encourages the realization of strategic alignment.

The second issue of the research question is how to ensure the consistency of the service transition strategy with the PSS business model. Several prominent research studies have been done on the topic of the PSS business model. Chiu et al. [79] introduced a systematic method to develop the PSS business model by utilizing two aspects of the business model, i.e., business model transformation (Phase 1) and business model evaluation (Phase 2). Phase 1 guides the identification of product or core competence, searching for target customers, market analysis, value chain construction and cost revenue estimation which lead to the development of alternatives of the business model. The alternatives are assessed through a decision making process (Phase 2) using the analytic hierarchy process (AHP) and the technique for order of preference by similarity to ideal solution (TOPSIS) analysis.

Among business model concepts, business model canvas (BMC) [57] is a notable reference model adopted in the PSS research $[26,27,71,80]$. Paula et al. [71] specifically identified the characteristics of PSS in each element of BMC to guide the development of a new PSS business model. This study also diagnosed the elements of BMC which potentially bring challenges during business model transformation. The transformation itself covered the three possible business models, i.e., product-, use- and result-oriented PSS. In another research on this topic, Adrodegari et al. [26,27] developed a hierarchical framework of PSS business model based on BMC. Each element of BMC was derived into a second-order variable serving as a pivotal consideration to design a new PSS business model. The framework consisted of derivation variables from each element of the PSS business model. The managerial question (challenge) of each variable supports the company to consistently plan the action to implement that business model.

These findings lead to the conclusion that due to its high applicability and comprehensiveness to represent elements of a business model and to facilitate the development of PSS business models, BMC is certainly a compatible tool visualizing existing or new PSS business model. The four-perspective strategy map demonstrates pivotal components in the organization including tangible and intangible assets. It generally represents the element of the business model including the nine building blocks of BMC. By clearly identifying the relationship between the perspectives of strategy maps and the elements of BMC, the effort to facilitate strategic alignment between them is achievable. Based on the 
insights obtained during the literature review, a PSS business alignment framework is developed and proposed to answer the research question.

The combination of the strategy map and BMC is expected to strengthen the manufacturer, allowing it to clearly plan its service transition in a more manageable fashion and accomplish alignment in its internal dimension. The word "manageable" emphasizes two substantial issues of the research question of this paper. The identification of the $\mathrm{SO}$ escalates the realization of service transition strategy, since the scope of the transformation process is specifically divided into relatively short-term action plans, clearly assigned to specific entities within the company and simply depicted in a single map which is apprehensible for non-management personnel. On top of that, service transition is planned based on and meriting a company-specific context, its internal capabilities, and the external forces. This certainly supports the notion that the journey towards service transition can be logically different considering the company's specific context [62]. The second premise of this proposal is that the alignment between strategy and business model implies consistency in the effort to realize service transition from strategic to operational levels. The proposed framework affords the opportunity to translate the big and complex transition process into a manageable and structure action plan. Eventually, those two premises make service transition more manageable.

The proposed framework consists of two main components as shown in Figure 4. Step 1 aims to develop a strategy map of service transition for the company, while the main goal of step 2 is linking the identified SOs into business model elements denoting the way the company runs its PSS business to achieve the identified SOs. Each step of the proposed framework is further explained in Sections 4.3.1 and 4.3.2.

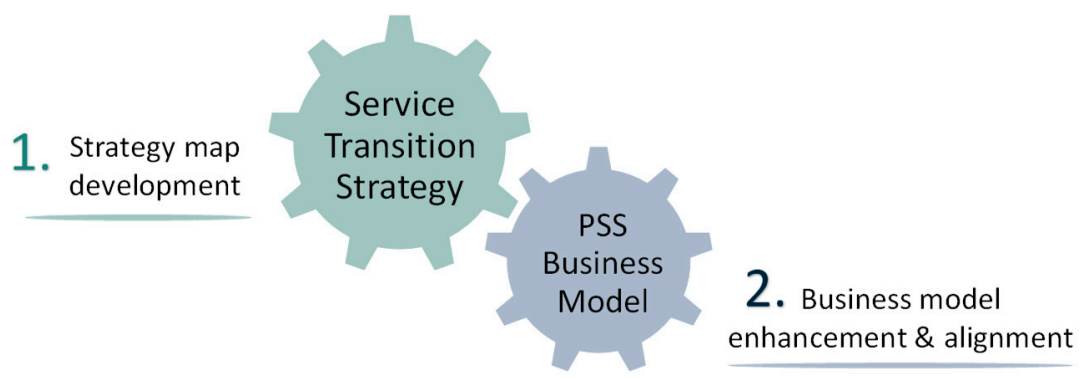

Figure 4. The proposed framework PSS strategic alignment.

\subsubsection{Step 1 Strategy Map Development}

Step 1 is translated into detailed steps (denoted in Figure 5) including internal and external analysis, strategic objective (SO) identification, and mapping the identified SO in a strategy map of service transition. The process is started by conducting internal and external analysis. As part of this research project, a particular internal and external analysis for the company embarking on the service transition (step 1.1) has been discussed through the study of [62]. The proposed internal and external analysis is the modification of the original SWOT analysis to be a structured and quantified assessment by involving identified key capabilities of service transition.

In [62], the internal and external assessment is reflected in a set of questions with the evaluation score of between +5 (maximum) and -5 (minimum). The modification of the original SWOT analysis into a structured assessment is aimed to prevent fuzzy discussion and unfocused direction. The analysis enables the company to evaluate its condition compared to the required capabilities for service transition. Therefore, the future SO can be identified to be focused on the expansion of the inadequate capabilities. Figure 6 provides an illustration of the proposed internal and external analysis from the study of [62]. 
1

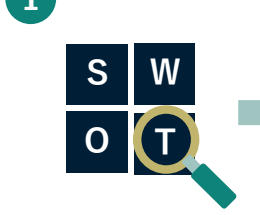

Internal and external analysis
2.

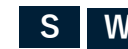

0

T

西
Strategic objective identification

3

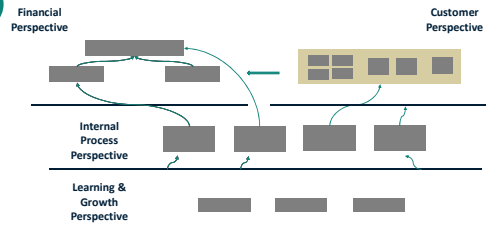

Strategy map development

Figure 5. The detailed procedure of step 1.

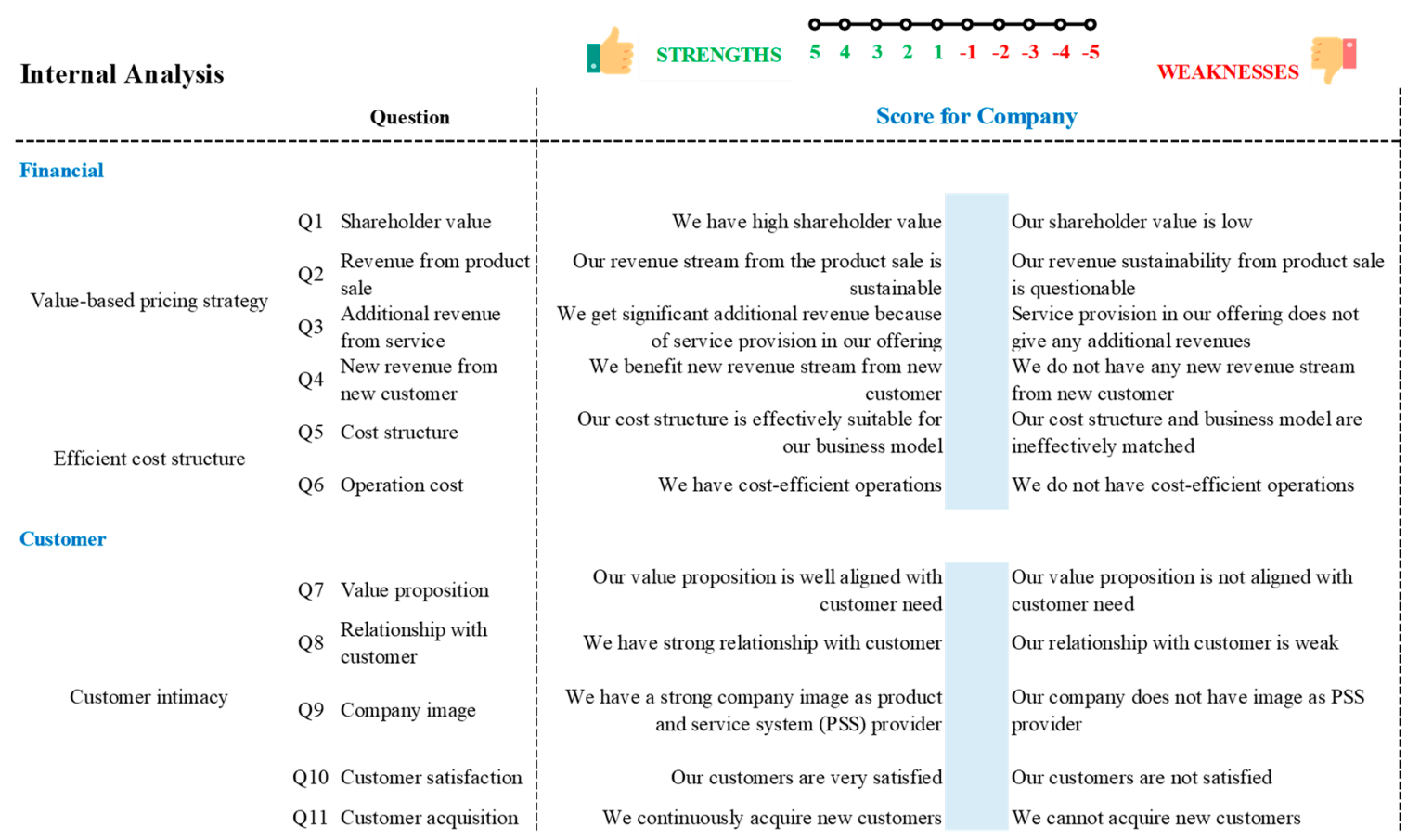

(a)

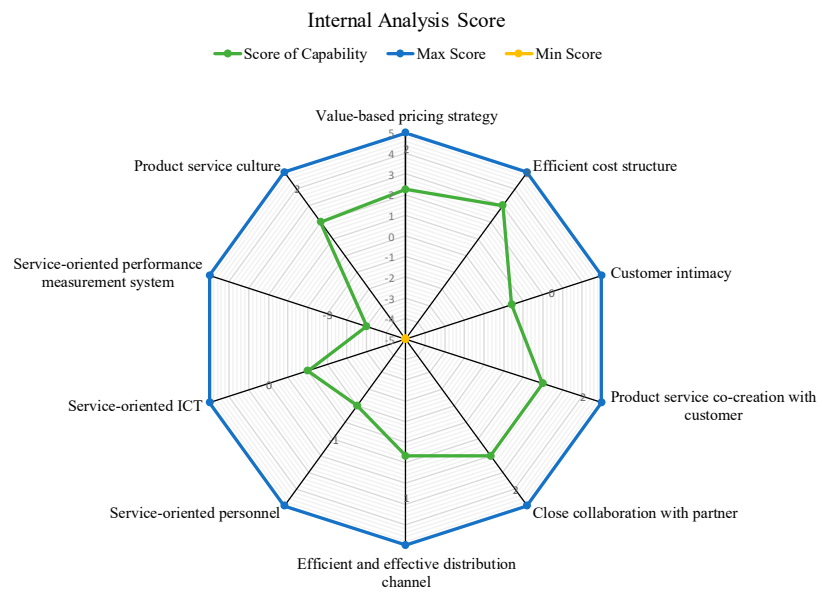

(b)

Figure 6. (a) The Illustration of the internal and external analysis for a company undertaking the service transition. (b) The illustration of a radar diagram as the result of internal and external analysis [62].

The recapitulated scores of internal and external analysis are plotted into a radar diagram to visually present the current condition of the company compared to the desired capabilities for service 
transition. Considering the shortcoming of required capabilities, the company is guided to identify SOs to improve its condition. The modified SWOT matrix of [78] is utilized to identify SOs by thoroughly considering the current capabilities and external forces of the company. Since the internal analysis and external analysis are built upon the requisite capabilities for service transition, the result of SO identification remains consistent with capability development for service transition.

After formulating SOs, the identified SOs are organized to compose a strategy map. This paper introduces a new structural arrangement of the four perspectives of the strategy map [74]. The new arrangement is proposed in consideration of the characteristics of PSS. The customer perspective is traditionally placed under the financial perspective which indicates that financial perspective is the ultimate priority and leading goal of the company. A leading perspective can be achieved if the lagging (other) perspectives placed beneath it have been achieved. However, considering the long term, close relationship and value co-creation paradigm between a PSS company and its customer, it is suggested that the customer perspective has the same importance as the financial perspective. The strong customer-centricity is the key feature of a PSS company [10]. The relations between customer and company are intensively developed and managed beyond the traditional interaction $[1,28,71]$. A PSS company is very much customer-centric, based on the context of its customer value proposition $[61,81,82]$. Therefore, a new arrangement of the strategy map of the service transition is proposed and presented in Figure 7.

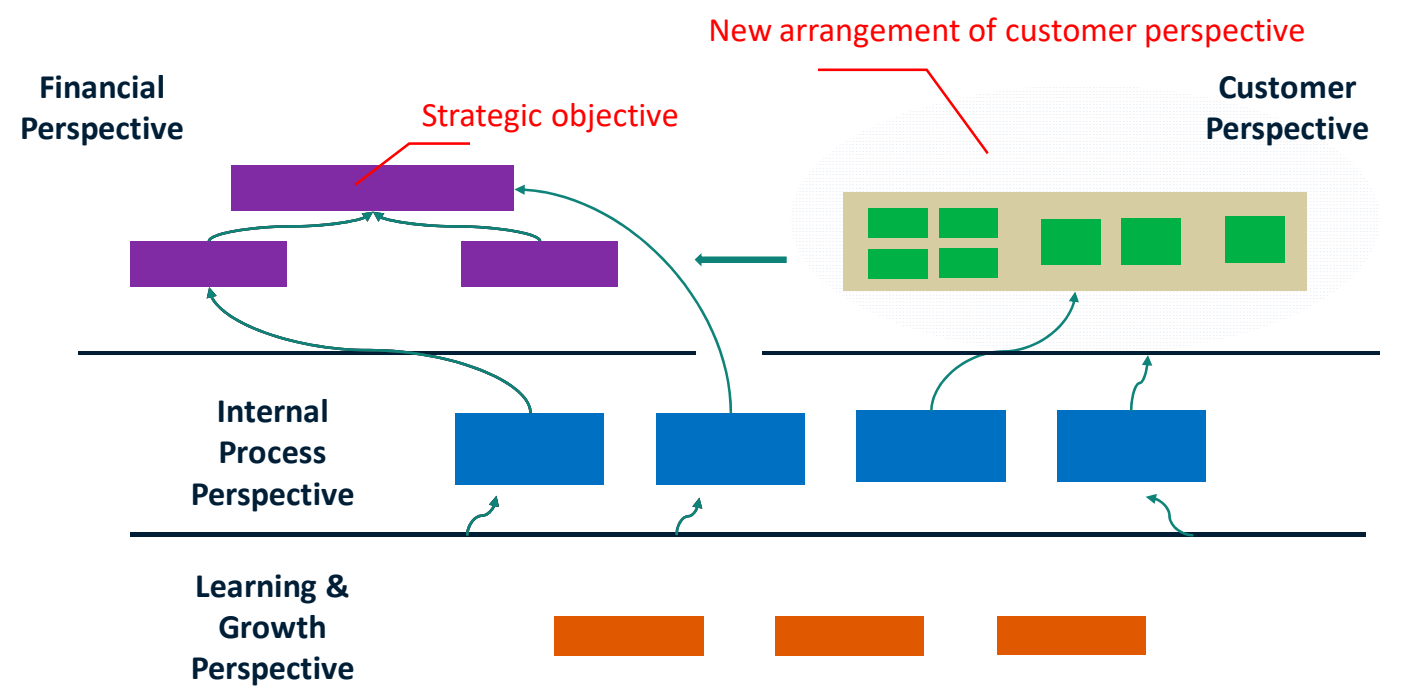

Figure 7. The new structure of strategy map for the service transition (modification of the original strategy map [74]).

Following the mapping step, identifying the cause-and-effect relationship among SOs is needed. This step attempts to connect a leading SO with its driver, or lagging SO. There are a considerable number of proposals that specifically define the causal relationship in the strategy map. A fuzzy decision making trial and evaluation laboratory (DEMATEL) framework is proposed for modeling the cause-effect relationship in a strategy map [83]. This framework is then extended and incorporated with the fourth generation of the balanced scorecard to achieve a more quantitative relationship identification [84]. Of note, another proposal utilizes structural equation modeling (SEM) [85]. However, in this study, the identification of causal relationships among SOs can be manually defined by the company, since the causal relationship can be adjusted based on logical relation between one SO to another. As an illustration, an SO in the financial perspective is a leading goal that can be achieved if another perspective has been well implemented and achieved.

Step 1 presents the uniqueness of the PSS strategic alignment since service transition strategy is deployed into detailed SOs. The deployment highly relies on the company's own internal capabilities and external forces. The structured and quantified internal and external analysis for service transition 
makes the SO identification specific in grasping the context of transformation (the situation) and planning the process of transformation (what changes). The adoption of the new structure of the strategy map in the proposed framework enables clear and easy communication of the company's service transition goal, thus the shared understanding is realized at various levels and within various units of the company.

\subsubsection{Step 2 Business Model Enhancement and Alignment}

Since the business model is the reflection of the selected strategy [52], it supposedly leads to the same direction as the company's strategy. To realize the alignment between strategy and business model, it is necessary to firstly clarify the relation between the four perspectives of the strategy map and the nine elements of the BMC. The alignment can be realized if SOs from the perspective of the strategy map are well reflected in the elements of the BMC. Hence, the realization of the correlated elements of the BMC determine the successful achievement of the SOs. The knowledge stock of the literature review is utilized to define the relations among the perspectives of the strategy map and the elements of the BMC, as illustrated in Figure 8. Table 4 presents the theoretical base to support the identified relations.

\section{Element of Business Model Canvas}

\section{Perspectives of Balanced Scorecard in Strategy Map}

Financial Perspective

Customer Perspective

Internal Business Process

Learning and Growth

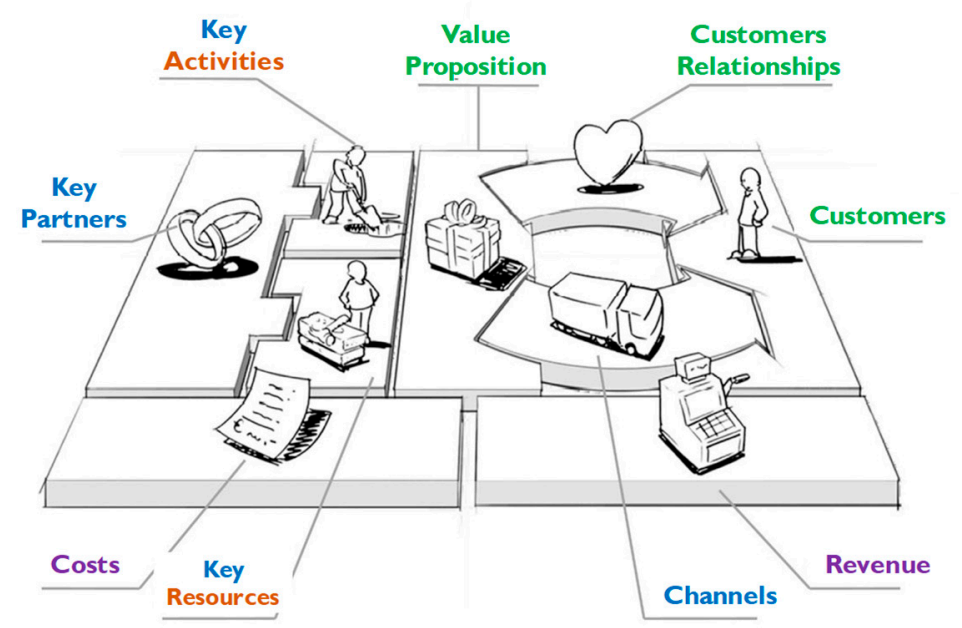

Figure 8. The relations of perspectives in a strategy map with the elements of the business model canvas (BMC) (based on $[57,74]$ ).

The identified SOs in step 1 are inputs or considerations to conceptualize the element of PSS business model. The identified relations in Table 4 are expected to support the company to ensure the alignment between these two aspects. A question of "does our business model support the realization of the strategic objectives of our PSS strategy?" should be able to be responded to affirmatively. In other words, any strategic objective set in a particular perspective needs to well reflected in the associated element of the business model. 
Table 4. Relations of the perspectives of the strategy map and the elements of the BMC.

\begin{tabular}{|c|c|c|c|c|}
\hline & $\begin{array}{c}\text { Perspectives in } \\
\text { Strategy Map }[74,76,86]\end{array}$ & \multicolumn{2}{|c|}{$\begin{array}{l}\text { Correlated Elements in } \\
\text { BMC [57] }\end{array}$} & $\begin{array}{l}\text { References to Adjust the } \\
\text { Relation }\end{array}$ \\
\hline \multirow[b]{2}{*}{ Financial } & \multirow{2}{*}{ Leading indicators related to the company's financial health and performance } & Cost & $\begin{array}{l}\text { The incurred cost as a consequence } \\
\text { of running the business }\end{array}$ & {$[4,29,35,71]$} \\
\hline & & Revenue Stream & $\begin{array}{c}\text { Represents revenue generated by the } \\
\text { company from serving a customer } \\
\text { segment }\end{array}$ & {$[14,16,25,71]$} \\
\hline \multirow{3}{*}{ Customer } & \multirow{3}{*}{$\begin{array}{l}\text { Lagging indicators related to customers and their value proposition. This } \\
\text { perspective defines how the company differentiates itself to attract, retain and } \\
\text { deepen relationships with customers }\end{array}$} & Value Proposition & $\begin{array}{l}\text { The bundle of products and/or } \\
\text { services which creates value for a } \\
\text { specific customer segment }\end{array}$ & {$[58,65,81,82]$} \\
\hline & & Customers & $\begin{array}{l}\text { Defines the different groups of } \\
\text { people or organizations the company } \\
\text { aims to reach and serve }\end{array}$ & {$[10,23,61]$} \\
\hline & & $\begin{array}{l}\text { Customer } \\
\text { Relationships }\end{array}$ & $\begin{array}{l}\text { The type of relationship established } \\
\text { by the company for a particular } \\
\text { customer segment }\end{array}$ & {$[1,16,28,71]$} \\
\hline \multirow{4}{*}{$\begin{array}{l}\text { Internal } \\
\text { Business } \\
\text { Process }\end{array}$} & \multirow{4}{*}{$\begin{array}{l}\text { The internal process perspective captures the critical process and what the } \\
\text { company does to deliver the value proposition }\end{array}$} & Channels & $\begin{array}{l}\text { The ways that the company reaches } \\
\text { the customer to deliver the value } \\
\text { proposition }\end{array}$ & {$[25,35,87]$} \\
\hline & & Key Activities & $\begin{array}{l}\text { The most important things that } \\
\text { should be done to run the business }\end{array}$ & {$[25,88]$} \\
\hline & & Key Resources & $\begin{array}{l}\text { The most crucial assets required to } \\
\text { run the business }\end{array}$ & {$[25,89,90]$} \\
\hline & & Key Partners & $\begin{array}{l}\text { The network of suppliers and } \\
\text { partners to run the business }\end{array}$ & {$[25,35,87]$} \\
\hline \multirow{2}{*}{$\begin{array}{l}\text { Learning and } \\
\text { Growth }\end{array}$} & \multirow{2}{*}{$\begin{array}{l}\text { The learning and growth perspective defines intangible assets of the company } \\
\text { including the human capital (core competencies and skills), information } \\
\text { capital (technologies), and organization capital (the corporate culture) required } \\
\text { to support the company's strategy }\end{array}$} & Key Activities & $\begin{array}{l}\text { The most important things that } \\
\text { should be done to run the business }\end{array}$ & {$[25,88]$} \\
\hline & & Key Resources & $\begin{array}{l}\text { The most crucial assets required to } \\
\text { run the business }\end{array}$ & {$[36,37,70,72]$} \\
\hline
\end{tabular}




\section{Empirical Development of PSS Strategic Alignment}

This section presents the application of the proposal in the two cycles of action research. It is followed by a discussion of the results obtained from the action research that leads to further development of PSS Strategic Alignment.

\subsection{Action Research Cycle 1}

The first cycle of action research was conducted in a 3-hour workshop in the innovative design laboratory in Tokyo, Japan. The workshop was started with an explanation of the framework and the supporting method. The presentation highlighted the logic and theoretical foundation to develop the proposal. It was then followed by a working group to apply the proposal. The participants worked separately in the 6 working groups of PSS business innovation projects in the design school. Each group has developed a PSS business model (BM) concept as an initiative of service transition intention. Thus, the working groups were set to benefit from the proposed framework in the embodiment of the service transition strategy and its alignment with the PSS BM idea. The 6 working groups worked in a similar sequence. By using the internal and external analysis (Figure 6), strategic objectives were identified so that a strategy map of service transition strategy was developed. The PSS BM idea was enhanced by utilizing the BMC. Finally, alignment was strived by analyzing every identified SO in strategy map was reflected and translated into the structural elements of BMC.

The evaluation of the action's consequence could not be done separately in the 6 working groups. Thus, an open discussion granted consolidation of findings that bear benefits for further empirical development of the proposal. Two evaluation dimensions from the method evaluation model [40] were used to facilitate the analysis i.e. perceived usefulness and perceived ease of use from the proposal. Perceived usefulness represents the degree to which a person believes that the proposal would be effective to achieve its intended objectives. The perceived ease of use implies to what extent a person believes that adopting the proposal would be free of effort.

The participants comprehended the potential usefulness of the proposal particularly its importance to advocate "appropriateness" of the company logic set towards PSS by bridging strategic and operational decision making. However, the fellow researchers found that the representation of the PSS strategic alignment framework (Figure 4) was not self-evident. The main premise of alignment between service transition strategy and the PSS business model was obscure. Because the flow of steps and the connection between the perspectives of the strategy map and the elements of BMC were not intelligible from the figure. Proceeding to Step 1, the participants scrutinized the proposed internal and external analysis [62]. The assessment was evaluated based on the relevance and appropriateness of the assessment representing the PSS required capabilities. As a consequence, the assessment points became 35 questions from the original 42 questions.

For the perspective of usability, the participants assumed the proposal would benefit in two aspects of improvement. The participants were unfamiliar with some terms in the proposal that triggered a difficulty to comprehend. Many researchers mainly had an engineering background, while the proposal used strategic management theories. This fact underlined the importance to use a prevalent language for the benefit of a multi-disciplinary team like PSS. Moreover, the framework application was done manually using the paper-based worksheets. The participants perceived this method as burdensome specifically for internal and external analysis. The assessment consists of several questions and include a score recapitulation. Thus, a supporting tool was expected to increase the ease of use.

Learning from the evaluation, the proposal was altered to advance the effectiveness to achieve its intended objective. The image of the proposed framework was revised to ensure it conveys a self-evident to illustrate the main premise of the research, as shown in Figure 9. The new framework includes a new structure of the PSS strategy map and the BMC. The color-coded is used to depict a connection between the perspective of the strategy map and the element of the BMC. The internal and external analysis was modified to accommodate the revision assessment. Concurrently an excel-based 
supporting tool was introduced to assist the internal and external analysis and SO identification. The supporting tool was expected to increase the proposal's usability. Besides, a management terminology glossary was included in the excel to prevent misconceptions of the specific management terms. The proposal refinement was then used in the second action research.
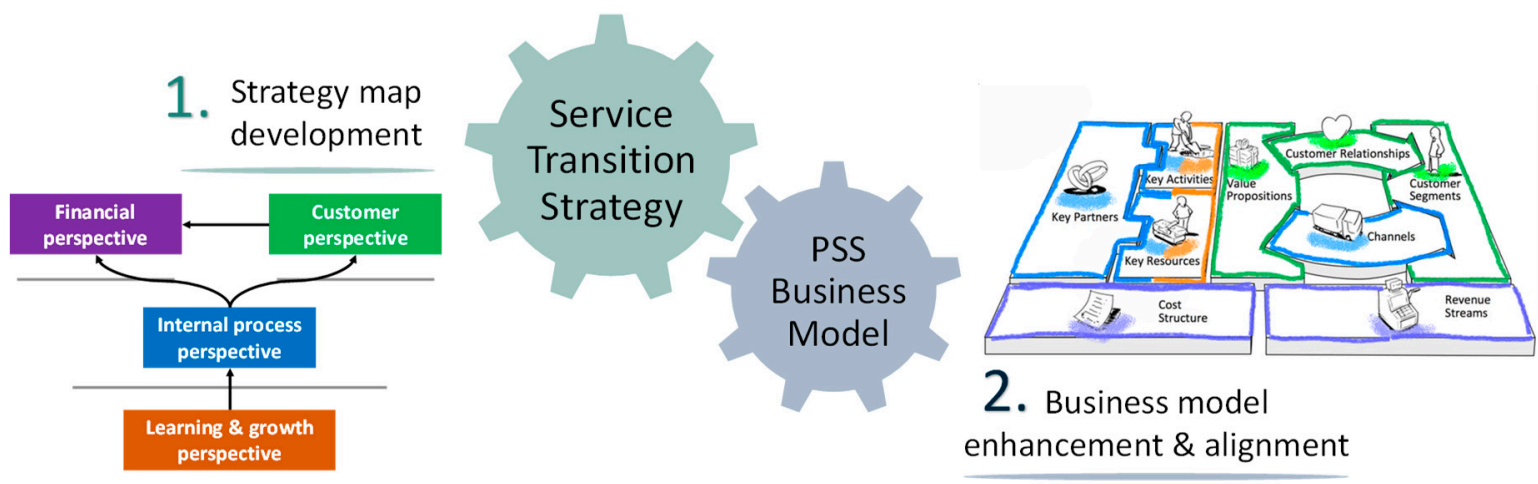

Figure 9. The revised PSS strategic alignment from the action research cycle 1 (based on $[57,74]$ ).

\subsection{Action Research Cycle 2}

The action research cycle 2 was conducted in the same manner as the action research cycle 1 , except for the involvement of practitioners from Japanese companies. Initially, the participants of the workshops were 30 people who were the middle to the high level of manager from 13 Japanese companies. However, only 13 people from 11 companies were willing to actively involved in the evaluation part of the action research. The 12 researchers from the action research cycle 1 were distributed to work in each working group as the facilitator. After getting an introduction presentation, the 6 working groups applied the proposal. The altered version proposal from the action research cycle 1 was used. The scheduled workshops for this action research were only 2 times, but the working groups have conducted separate meetings outside the scheduled workshops to continuously work on this framework. Since there were fellow researchers in each working group, here the actions of the participants remain being monitored.

The same evaluation dimensions were used to appraise the consequence of the action in this cycle. However, all the evaluation points from the practitioners interestingly laid under the perceived usefulness. The proposal was developed using a top-down approach in which the alignment is realized by translating the SOs of service transition strategy into elements of the PSS business model. This translation means the elements of BM supposedly assist the realization of the identified SOs. The practitioners argued that strategic alignment was not merely a top-down direction, but also a bottom-up direction. The transition towards PSS in some cases was initiated by a business model innovation even before a clear intention of service transition formed in the strategic level of the company. In this case, the intention to be PSS is triggered by the business innovation initiative. Hence, the alignment initiative can be driven from the operational level then expanded to the strategic level (bottom-up approach).

The practitioners acknowledged the modification of original SWOT analysis into a structured assessment has led to more focused discussion. However, the assessment was tremendous because of the unavailability of supporting data. The practitioners suggested the internal and external analysis is facilitated by the data collection. They argued that each point of assessment needs supporting data where the assessment can be given based on that evidence. The practitioners regarded the negative score was complicated. Thus, the original Likert scale was preferred since it provides a clear and convenient evaluation. Moreover, the capacity analysis of the company was believed as an essential foundation in identifying SO. The identification of SOs was meant to improve the inadequate internal capabilities as required for service transition. Improving all inadequate capabilities may require extensive resources encompassing tangible and intangible assets. Unfortunately, these resources can be limited or even scarce in real practice. Therefore, the practitioners conveyed advice to include 
a decision process to select which inadequate capability(s) to be targeted for improvement. This additional step can increase the applicability of the proposal in real practice.

Another formal feedback provided by the practitioners was a scale-based evaluation. Considering the small sample size of the collected data, the inter-item correlation analysis, and Cronbach's alpha were used to test the validity and the reliability of the questionnaire, respectively. The statistical tests infer that the perception-based variables from this data are reliable to be used to conclude. The average values for D3, D4, and D5 were 2.79, 3.54, 3.46, respectively, out of 5. It indicates the intention of using the proposed framework from respondents is noticeably high. It reflects positive feedback on the proposed framework. To further examine the applicability of the proposed framework, a likelihood of adoption in practice was analyzed by using the one-sample $t$-test. The values of all variables were significantly positive and this means the proposed framework has a high likelihood of being implemented in practice.

Regarding the performance-based variable D1, in general, participants considered the required time to implement the proposed framework to be high. A product developer manager stated: "It takes a lot of time to implement the proposed framework. But time is not a big problem if we seriously consider the evaluation and overall planning step to be a PSS provider". A business innovation manager from the service company articulated that it would be better to divide the task into short-term concentrations due to the considerable involvement of strategic management and operational management of the company. For performance-based variable D2, most of the participants could not openly justify the quality of the deliverables from the implementation of the proposed framework. An operation manager of the retail department stores expressed: “I don't have enough judgment to evaluate the deliverables. However, I thought it would be easier to assess the output if I am in a position to conduct business decisions". Furthermore, some participants from the design center and planning department argued that the time frame limitation of the workshop significantly influenced the quality of the output. However, they stated each tool worked effectively and were relevant to the overall objective of the framework if the preconditions were clarified.

\subsection{Discussion of The Action Research Result and Empirical Version of PSS Strategic Alignment}

This section compiles the result of the conducted action research, particularly from the second cycle. A discussion on key findings is presented to further enhance the proposal. The evaluation dimension of usefulness and ease of use remain to be used to structure the discussion.

The strategic alignment in PSS literature is studied mainly based on the horizontal scope of analysis. Either from the internal dimension $[15-17,22-27,35,37,67,70]$ of the company or the external alignment $[30,31,68,71]$ involving elements of the service ecosystem. The action research cycle 2 advances this concept in which two directions of alignment are feasible under the vertical scope of analysis i.e. top-down alignment and bottom-up alignment. It reveals that the intention to achieve strategic alignment is attainable through a top-down and bottom-up approach. As emphasized by [3], PSS development is not always a linear process that follows a top-down direction. PSS business development does not specifically require to be derived from company strategy. The development process can be independently and concurrently conducted. Therefore, the alignment between the PSS business model and company top-level strategy can be achieved using a top-down or bottom-up approach. The alignment direction can be either way, as long as each element of the PSS business model fully reflects the effort of the implementation of the service transition strategy.

The modification of the original SWOT analysis to be a structured assessment allows the practitioners to evaluate the company's condition compared to the required capabilities of PSS. However, an evidence-based analysis is fundamental in strategic decision making. To ensure the future strategies can be set to expand of the inadequate capabilities, SO identification needs to be conducted above the solid evidence. This fact leads to the requirement of contextual data which represents the current capabilities of the company. The inclusion of contextual data in analysis supports the hypothesis of [63], where the strategy of service transition demands to be reviewed in the context of transformation 
(the situation). In addition to the evidence-based analysis, the rationality of the action plan is another crucial aspect of strategic decision making. The practitioners advocate a rational analysis in targeting which inadequate capabilities are selected to be further enhanced in the formulated SO. It is intended to direct the company's capability effectively to improve the inadequate capabilities for PSS.

These key findings act as a valuable source of empirical development of the proposal. Figures 10 and 11 present the altered version of the proposal. The arrows in Figure 10 depict the alignment direction in which either from a top-down or bottom-up approach. A contextual data collection is added in Step 1, followed by a reconstruction of the remaining steps to incorporate the capability targeting (Figure 11). The contextual data is identified in each assessment point of internal and external analysis. This addition is also embedded in the supporting excel tool to ensure the practicability of use.

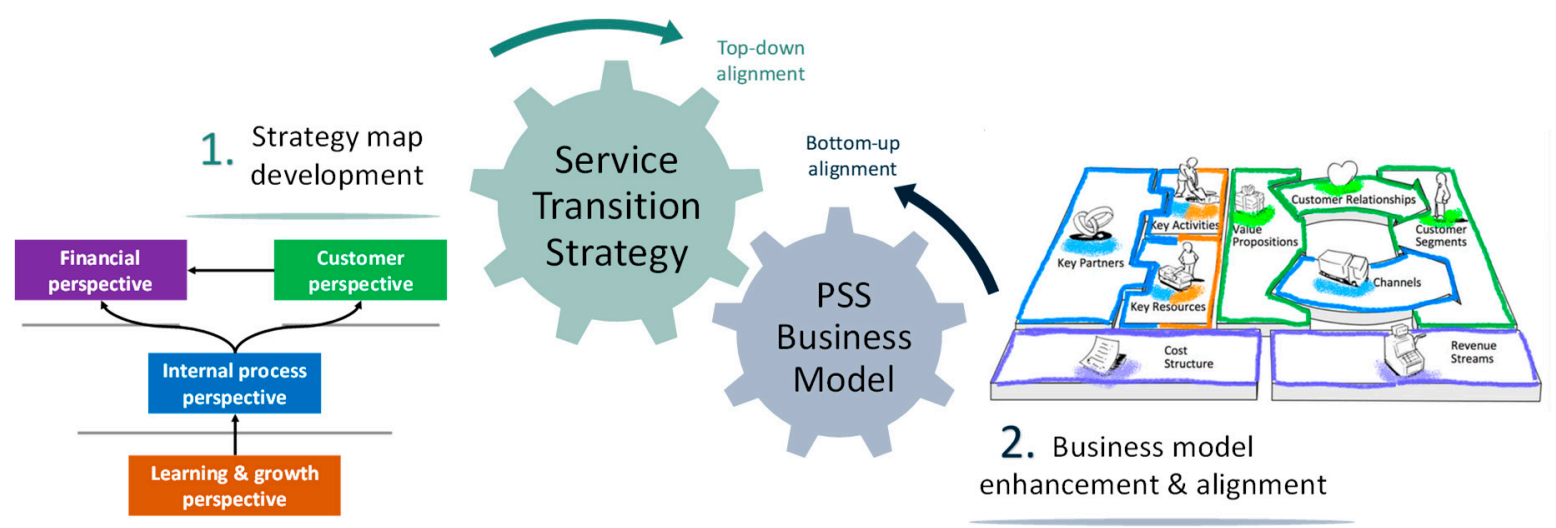

Figure 10. The revised PSS strategic alignment from the action research cycle 2 (based on $[57,74]$ ).

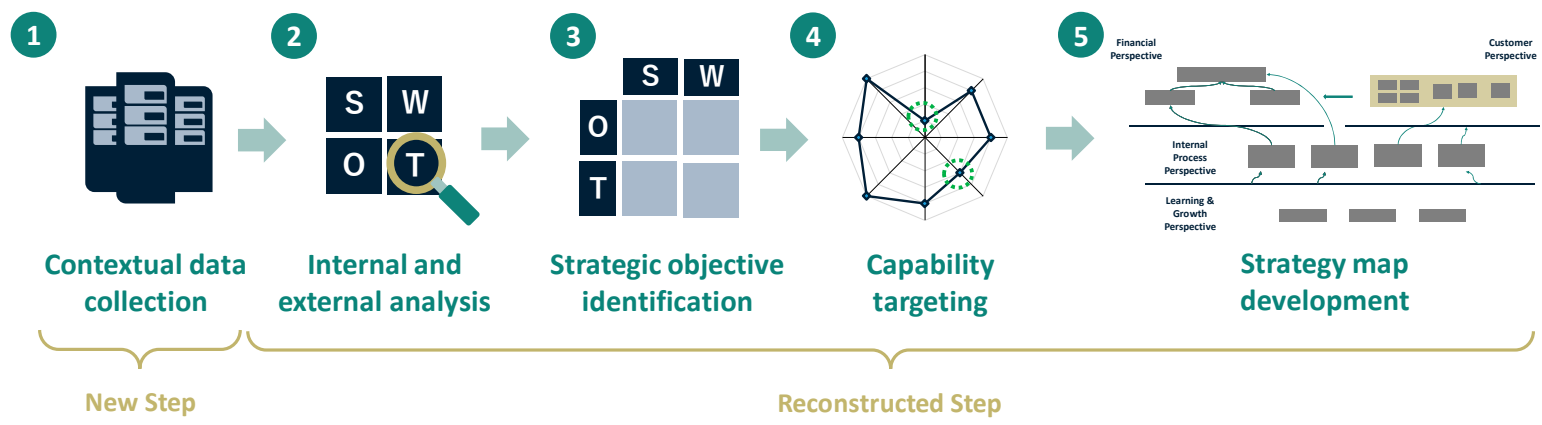

Figure 11. The revised step 1—strategy map development.

The best beneficiary of the proposal is a manufacturer which intends to embark on the service transition or in the early stage of the journey. The empirical version of the PSS strategic alignment affords the manufacturer to structure and formalize the service transition strategy and then connect it to the PSS business model to harmonize strategic and operational levels in the pursue of PSS. The following Figure 11; Figure 12 is the illustration of how a manufacturer can use the proposal in the case of a top-down approach. Figure 13 presents the final result of a working group in the action research cycle 2 using the step by step of the proposal. 


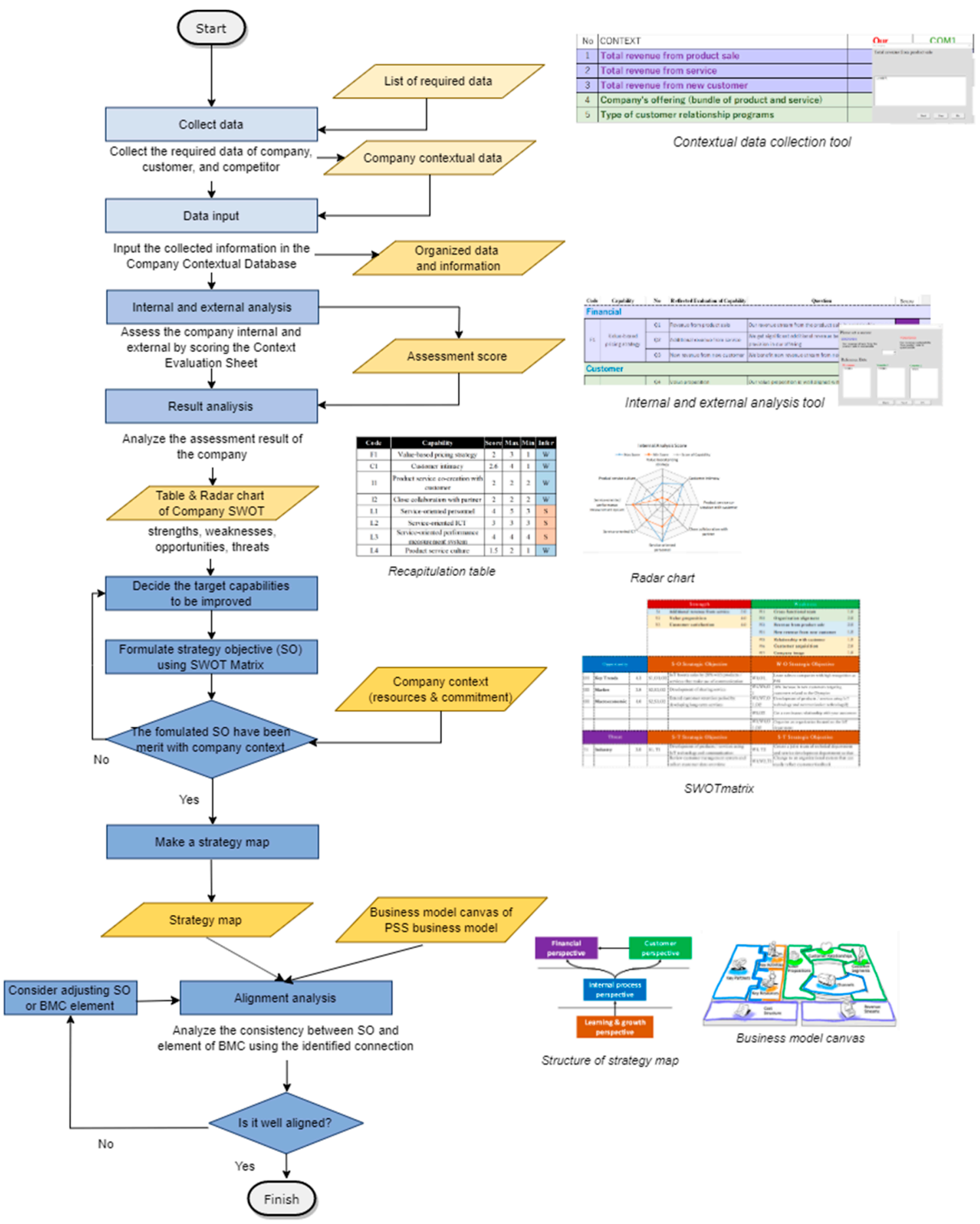

Figure 12. The illustration of how a manufacturer can use the proposal in the case of a top-down approach. 


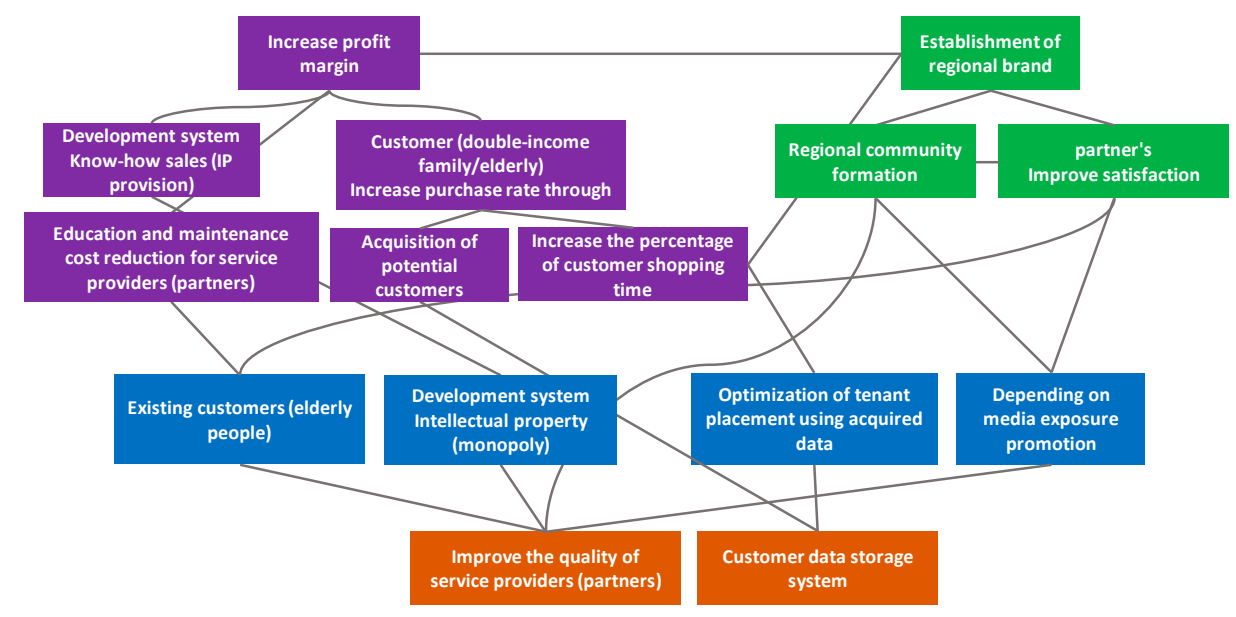

(a)

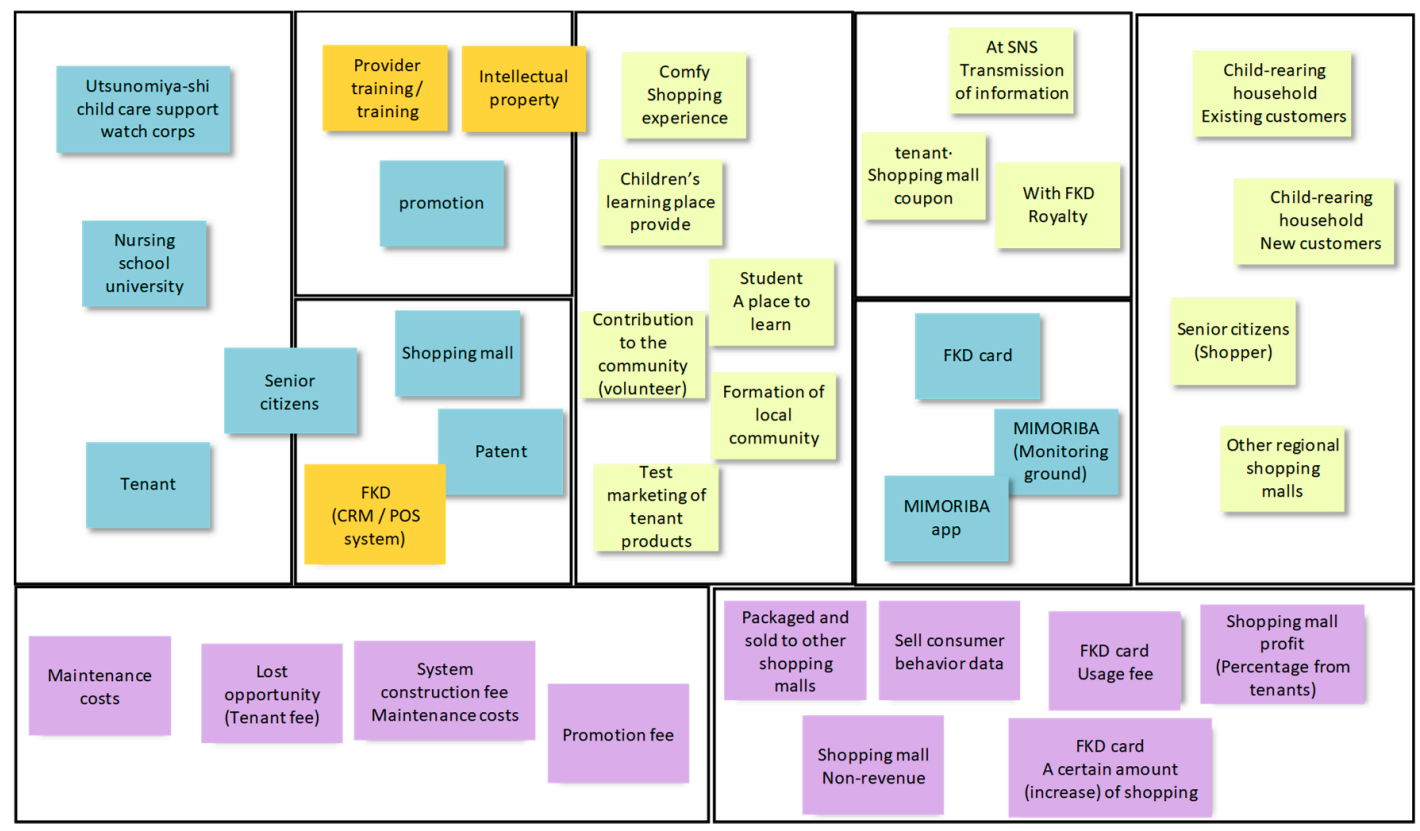

(b)

Figure 13. An example of the working group result in implementing the proposal. (a) The strategy map. (b) A PSS business innovation in a childcare service provider.

\section{Conclusions}

As there is a continuous increase of global competition which forces the manufacturer to achieve sustainable economic, social, and environmental benefits, the concept of PSS has increasingly gained attention [15]. However, transforming traditional business models into PSS business model, as known as a service transition $[10,11]$, triggers inconsistencies between strategic direction and organizational arrangement at the operational level [10,13-15]. These inconsistencies may hinder the promising benefits of PSS and lead to a service paradox [16]. Nonetheless, strategic alignment is occasionally neglected [24], and limited academic works have concretely supported the intention to achieve this alignment. To bridge the gap, the presented paper has explored the relevance and importance of strategic alignment between service transition strategy and PSS business model and proposed the PSS strategic alignment and supporting method.

Through a systematic literature review, it is revealed that limited studies have contributed to strategic alignment in service transition. This is reflected by the number of research studies focusing 
on this topic. However, the collected articles have greatly emphasized the relevance and importance of strategic alignment in service transition $[13,17,24,31,66-69]$. The consistency among several internal elements enables the transition from product to service, while the absence of internal consistency is a pivotal risk factor for commercial and operational aspects of PSS. Most importantly strategic alignment is a key success factor of the journey towards being a PSS company. A consistency between service transition strategy and PSS business model is the most highlighted pivotal alignment in the literature.

The theoretical version of the proposal has been developed based on the knowledge stock of original strategic alignment in strategic management research. An alignment between service transition strategy and PSS business model is promoted by employing strategic objective (SO) of strategy map and element of the business model canvas (BMC). The connection of identified SOs of service transition strategy and element of BMC aims to ensure internal elements of a manufacturer harmoniously and concurrently work together in the service transition journey. Then, this proposal has been revised and further improved based on the two cycles of action research as shown in Figures 10 and 11.

The present research contributes to the literature by systematically identifying the importance of roles (Table 2) as well as the dimension and its pertinent elements (Table 3) of strategic alignment in service transition. This research can be regarded as the first systematic literature review specifically focuses on strategic alignment in PSS. In this sense, this research fosters the maturity of PSS research by adopting strategic management theory as acknowledged by some previous studies [11,36,37,63-65]. This research extends the premise of previous studies on the internal alignment of PSS research [15-17, $22-27,35,37,67,70]$. A practical endeavor is conceptualized to achieve strategic alignment by connecting service transition strategy and PSS business model. This attempt bridges the topic of strategy and business model in PSS research. Vertical analysis of alignment (top-down and bottom-up) is also introduced to enrich knowledge stock of the alignment dimension. Another contribution is the connection between SOs and BM elements not only assists the realization of strategic alignment but also enables the manufacturer to concurrently direct and implement its service transformation. The service transition strategy is deployed into specific, measurable, achievable, relevant, and time-bound (SMART) short term targets. The adoption of the strategy map serves an effective visualization to disseminate the company's intention to relevant stakeholders.

However, some parts of this research call for more attention to be further developed. The overall process of the proposed framework is considered to require a long time to proceed. The implementation of the proposed framework ideally requires the involvement of multi-level decision-makers within the company since the company's strategic plan and business innovation are more as a cross-level management responsibility. As a result, complexity in the decision process may arise. The proposed framework is also unable to quantitatively measure the degree of alignment between SO and business model elements. Hence, these facts bring the opportunity for future work related to the topic. The proposed framework can be possibly extended to the tactic level and performance measurement as the subsequent logical step in company management.

Author Contributions: Conceptualization, M.S., T.M., Y.M. and Y.S.; Data curation, M.S., T.M. and Y.M.; Formal analysis, M.S. and T.M.; Investigation, M.S. and T.M.; Methodology, M.S. and T.M.; Project administration, Y.M.; Resources, Y.M. and Y.S.; Supervision, Y.S.; Validation, M.S., T.M., Y.M. and Y.S.; Visualization, M.S. and T.M.; Writing—original draft, M.S.; Writing—review \& editing, M.S., Y.M. and Y.S.

Funding: This research was funded by Japan Society for the Promotion of Science, grant number 16K12667.

Acknowledgments: The authors would like to convey their gratitude to the participants of the action research. The participants' engagement and constructive feedback made this research happen.

Conflicts of Interest: The authors declare no conflict of interest. 


\section{References}

1. Mont, O. Institutionalisation of sustainable consumption patterns based on shared use. Ecol. Econ. 2004, 50, 135-153. [CrossRef]

2. Annarelli, A.; Battistella, C.; Nonino, F. Product service system: A conceptual framework from a systematic review. J. Clean. Prod. 2016, 139, 1011-1032. [CrossRef]

3. Tukker, A. Product services for a resource-efficient and circular economy-A review. J. Clean. Prod. 2015, 97, 76-91. [CrossRef]

4. Mont, O.; Dalhammar, C.; Jacobsson, N. A new business model for baby prams based on leasing and product remanufacturing. J. Clean. Prod. 2006, 14, 1509-1518. [CrossRef]

5. Beuren, F.H.; Ferreira, M.G.G.; Miguel, P.A.C. Product-service systems: A literature review on integrated products and services. J. Clean. Prod. 2013, 47, 222-231. [CrossRef]

6. Boehm, M.; Thomas, O. Looking beyond the rim of one's teacup: A multidisciplinary literature review of Product-Service Systems in Information Systems, Business Management, and Engineering \& Design. J. Clean. Prod. 2013, 51, 245-260.

7. Kohtamäki, M.; Partanen, J.; Parida, V.; Wincent, J. Non-linear relationship between industrial service offering and sales growth: The moderating role of network capabilities. Ind. Mark. Manag. 2013, 42, 1374-1385. [CrossRef]

8. Shimomura, Y.; Nemoto, Y.; Kimita, K. State-of-Art Product-Service Systems in Japan-The Latest Japanese Product-service Systems Developments. Procedia CIRP 2014, 16, 15-20. [CrossRef]

9. MacArthur, E. Towards the Circular Economy, Economic and Business Rationale for an Accelerated Transition; Ellen MacArthur Foundation: Cowes, UK, 2013.

10. Baines, T.S.; Lightfoot, H.W.; Benedettini, O.; Kay, J.M. The servitization of manufacturing: A review of literature and reflection on future challenges. J. Manuf. Technol. Manag. 2009, 20, 547-567. [CrossRef]

11. Rabetino, R.; Harmsen, W.; Kohtamäki, M.; Sihvonen, J. Structuring servitization-related research. Int. J. Oper. Prod. Manag. 2018, 38, 350-371. [CrossRef]

12. Zhang, W.; Banerji, S. Challenges of servitization: A systematic literature review. Ind. Mark. Manag. 2017, 65, 217-227. [CrossRef]

13. Alghisi, A.; Saccani, N. Internal and external alignment in the servitization journey-overcoming the challenges. Prod. Plan. Control 2015, 26, 1219-1232. [CrossRef]

14. Oliva, R.; Kallenberg, R. Managing the transition from products to services. Int. J. Serv. Ind. Manag. 2003, 14, 160-172. [CrossRef]

15. Martinez, V.; Bastl, M.; Kingston, J.; Evans, S. Challenges in transforming manufacturing organisations into product-service providers. J. Manuf. Technol. Manag. 2010, 21, 449-469. [CrossRef]

16. Gebauer, H.; Fleisch, E.; Friedli, T. Overcoming the service paradox in manufacturing companies. Eur. Manag. J. 2005, 23, 14-26. [CrossRef]

17. Crowley, E.; Burton, J.; Zolkiewski, J. Servitization intent as a factor in the servitization process. J. Bus. Ind. Mark. 2018, 33, 1125-1140. [CrossRef]

18. Chorn, N.H. The "alignment" theory: Creating strategic fit. Manag. Decis. 1991, 29, 20-24. [CrossRef]

19. Chandler, A.D. Strategy and Structure: Chapters in the History of the Industrial Enterprise; MIT Press: Cambridge, MA, USA, 1990; Volume 120.

20. Yin, X.; Zajac, E.J. The strategy/governance structure fit relationship: Theory and evidence in franchising arrangements. Strategic Manag. J. 2004, 25, 365-383. [CrossRef]

21. Ladib, N.B.R.; Lakhal, L. Alignment between business model and business strategy and contribution to the performance: Empirical evidence from ICT Tunisian venture. J. High Technol. Manag. Res. 2015, 26, 168-176. [CrossRef]

22. Aurich, J.C.; Mannweiler, C.; Schweitzer, E. How to design and offer services successfully. CIRP J. Manuf. Sci. Technol. 2010, 2, 136-143. [CrossRef]

23. Kindström, D. Towards a service-based business model - Key aspects for future competitive advantage. Eur. Manag. J. 2010, 28, 479-490. [CrossRef]

24. Lightfoot, H.W.; Gebauer, H. Exploring the alignment between service strategy and service innovation. J. Serv. Manag. 2011, 22, 664-683. [CrossRef] 
25. Kindström, D.; Kowalkowski, C. Service innovation in product-centric firms: A multidimensional business model perspective. J. Bus. Ind. Mark. 2014, 29, 96-111. [CrossRef]

26. Adrodegari, F.; Saccani, N. Business models for the service transformation of industrial firms. Serv. Ind. J. 2017, 37, 57-83. [CrossRef]

27. Adrodegari, F.; Saccani, N.; Kowalkowski, C.; Vilo, J. PSS business model conceptualization and application. Prod. Plan. Control 2017, 28, 1251-1263. [CrossRef]

28. Baines, T.S.; Lightfoot, H.W.; Evans, S.; Neely, A.; Greenough, R.; Peppard, J.; Roy, R.; Shehab, E.; Braganza, A.; Tiwari, A.; et al. State-of-the-art in product-service systems. Proc. Instit. Mech. Eng. Part B J. Eng. Manuf. 2007, 221, 1543-1552. [CrossRef]

29. Meier, H.; Roy, R.; Seliger, G. Industrial product-service systems-IPS 2. CIRP Ann. Manuf. Technol. 2010, 59, 607-627. [CrossRef]

30. Parida, V.; Sjödin, D.R.; Wincent, J.; Kohtamäki, M. Mastering the transition to product-service provision: Insights into business models, learning activities, and capabilities. Res. Technol. Manag. 2014, 57, 44-52.

31. Hou, J.; Neely, A. Investigating risks of outcome-based service contracts from a provider's perspective. Int. J. Prod. Res. 2018, 56, 2103-2115. [CrossRef]

32. Tranfield, D.; Denyer, D.; Smart, P. Towards a Methodology for Developing Evidence-Informed Management Knowledge by Means of Systematic Review. Br. J. Manag. 2003, 14, 207-222. [CrossRef]

33. Cook, D.J.; Greengold, N.L.; Ellrodt, A.G.; Weingarten, S.R. The relation between systematic reviews and practice guidelines. Ann. Intern. Med. 1997, 127, 210-216. [CrossRef]

34. Falagas, M.E.; Pitsouni, E.I.; Malietzis, G.A.; Pappas, G. Comparison of PubMed, Scopus, web of science, and Google scholar: Strengths and weaknesses. FASEB J. 2008, 22, 338-342. [CrossRef]

35. Reim, W.; Parida, V.; Örtqvist, D. Product-Service Systems (PSS) business models and tactics-A systematic literature review. J. Clean. Prod. 2015, 97, 61-75. [CrossRef]

36. Martinez, V.; Neely, A.; Velu, C.; Leinster-Evans, S.; Bisessar, D. Exploring the journey to services. Int. J. Prod. Econ. 2017, 192, 66-80. [CrossRef]

37. Rabetino, R.; Kohtamäki, M.; Gebauer, H. Strategy map of servitization. Int. J. Prod. Econ. 2017, 192, $144-156$. [CrossRef]

38. Coghlan, D.B. Doing Action Research in Your Own Organization; SAGE Publications Limited: Thousand Oaks, CA, USA, 2005.

39. Coughlan, P.; Coghlan, D. Action research for operations management. Int. J. Oper. Prod. Manag. 2002, 22, 220-240. [CrossRef]

40. Moody, D.L. The method evaluation model: A theoretical model for validating information systems design methods. In Proceedings of the European Conference on Information Systems, Naples, Italy, 16-21 June 2003; p. 79.

41. Hu, P.J.; Chau, P.Y.K.; Sheng, O.R.L.; Tam, K.Y. Examining the Technology Acceptance Model Using Physician Acceptance of Telemedicine Technology. J. Manag. Inf. Syst. 1999, 16, 91-112. [CrossRef]

42. David, F.R. Strategic Management: Concepts and Cases; Prentice Hall: Upper Saddle River, NJ, USA, 2011.

43. McLean, R. Alignment: Using the balanced scorecard to create corporate synergies. Aust. J. Manag. 2006, 31, 367-369. [CrossRef]

44. Peters, T.J.; Waterman, R.H.; Jones, I. Search of Excellence: Lessons from America's Best-Run Companies; Harper and Row: New York, NY, USA, 1982.

45. Venkatraman, N.; Camillus, J.C. Exploring the concept of "fit" in strategic management. Acad. Manag. Rev. 1984, 9, 513-525.

46. Miles, R.E.; Snow, C.C. Designing strategic human resources systems. Organ. Dyn. 1984, 13, 36-52. [CrossRef]

47. Henderson, J.C.; Venkatraman, H. Strategic alignment: Leveraging information technology for transforming organizations. IBM Syst. J. 1999, 38, 472-484. [CrossRef]

48. Kathuria, R.; Joshi, M.P.; Porth, S.J. Organizational alignment and performance: Past, present and future. Manag. Decis. 2007, 45, 503-517. [CrossRef]

49. Trevor, J.; Varcoe, B. How Aligned Is Your Organization? Harvard Business Review Digital Articles. 7 February 2017. Available online: https://hbr.org/2017/02/how-aligned-is-your-organization (accessed on 23 March 2019).

50. Bracker, J. The historical Development of the Strategic Management Concept. Acad. Manag. Rev. 1980, 5, 219-224. [CrossRef] 
51. Evered, R. So what is strategy? Long Range Plan. 1983, 16, 57-72. [CrossRef]

52. DaSilva, C.M.; Trkman, P. Business model: What it is and what it is not. Long Range Plan. 2014, 47, 379-389. [CrossRef]

53. George, G.; Bock, A.J. The business model in practice and its implications for entrepreneurship research. Entrep. Theory Pract. 2011, 35, 83-111. [CrossRef]

54. Casadesus-Masanell, R.; Ricart, J.E. From strategy to business models and onto tactics. Long Range Planning 2010, 43, 195-215. [CrossRef]

55. Hitt, M.A.; Ireland, R.D.; Hoskisson, R.E. Strategic Management Cases: Competitiveness and Globalization; Cengage Learning: Boston, MA, USA, 2012.

56. Hill, C.W.L.; Jones, G.R.; Schilling, M.A. Strategic Management: Theory: An Integrated Approach; Cengage Learning: Boston, MA, USA, 2014.

57. Osterwalder, A.; Pigneur, Y. Business Model Generation: A Handbook for Visionaries, Game Changers, and Challengers; John Wiley \& Sons: Hoboken, NJ, USA, 2010.

58. Tukker, A. Eight types of product-service system: Eight ways to sustainability? Experiences from SusProNet. Bus. Strategy Environ. 2004, 13, 246-260. [CrossRef]

59. Tukker, A.; Tischner, U. Product-services as a research field: Past, present and future. Reflections from a decade of research. J. Clean. Prod. 2006, 14, 1552-1556. [CrossRef]

60. Tukker, A.; Tischner, U. New Business for Old Europe: Product-Service Development, Competitiveness and Sustainability; Routledge: Abingdon, UK, 2017.

61. Green, M.H.; Davies, P.; Ng, I.C.L. Two strands of servitization: A thematic analysis of traditional and customer co-created servitization and future research directions. Int. J. Prod. Econ. 2017, 192, 40-53. [CrossRef]

62. Sholihah, M.; Maezono, T.; Mitake, Y.; Shimomura, Y. Towards development a PSS business evaluation: Proposal of internal and external analysis for sevitizing manufacturers. Procedia CIRP 2019, 83, 363-368. [CrossRef]

63. Baines, T.; Ziaee Bigdeli, A.; Bustinza, O.F.; Shi, V.G.; Baldwin, J.; Ridgway, K. Servitization: Revisiting the state-of-the-art and research priorities. Int. J. Oper. Prod. Manag. 2017, 37, 256-278. [CrossRef]

64. Eloranta, V.; Turunen, T. Seeking competitive advantage with service infusion: A systematic literature review. J. Serv. Manag. 2015, 26, 394-425. [CrossRef]

65. Brax, S.A.; Visintin, F. Meta-model of servitization: The integrative profiling approach. Ind. Mark. Manag. 2017, 60, 17-32. [CrossRef]

66. Matthyssens, P.; Vandenbempt, K. Moving from basic offerings to value-added solutions: Strategies, barriers and alignment. Ind. Mark. Manag. 2008, 37, 316-328. [CrossRef]

67. Sousa-Zomer, T.T.; Magalhães, L.; Zancul, E.; Cauchick-Miguel, P.A. Exploring the challenges for circular business implementation in manufacturing companies: An empirical investigation of a pay-per-use service provider. Resour. Conserv. Recycl. 2018, 135, 3-13. [CrossRef]

68. Sato, C.E.Y. Value co-creation in the management of projects delivering integrated solutions: The case of BT Global Services in the UK. Int. J. Proj. Organ. Manag. 2018, 10, 54. [CrossRef]

69. Rajakallio, K.; Ristimäki, M.; Andelin, M.; Junnila, S. Business model renewal in context of integrated solutions delivery: A network perspective. Int. J. Strateg. Prop. Manag. 2017, 21, 72-86. [CrossRef]

70. Gebauer, H.; Paiola, M.; Edvardsson, B. A capability perspective on service business development in small and medium-sized suppliers. Scand. J. Manag. 2012, 28, 321-339. [CrossRef]

71. Paula, A.; Barquet, B.; Gouvea De Oliveira, M.; Amigo, C.R.; Cunha, V.P.; Rozenfeld, H. Employing the business model concept to support the adoption of product-service systems (PSS). Ind. Mark. Manag. 2013, 42, 693-704. [CrossRef]

72. Story, V.M.; Raddats, C.; Burton, J.; Zolkiewski, J.; Baines, T. Capabilities for advanced services: A multi-actor perspective. Ind. Mark. Manag. 2017, 60, 54-68. [CrossRef]

73. Vandermerwe, S.; Rada, J. Servitization of business: Adding value by adding services. Eur. Manag. J. 1988, 6, 314-324. [CrossRef]

74. Kaplan, R.S.; Norton, D.P. Having trouble with your strategy? Then map it. In Focusing Your Organization on Strategy - With the Balanced Score-Card; Harvard Business Review: Brighton, MA, USA, 2000.

75. Kaplan, R.S.; Norton, D.P. Transforming the balanced scorecard from performance measurement to strategic management: Part II. Account. Horiz. 2001, 15, 147-160. [CrossRef] 
76. Kaplan, R.S.; Kaplan, R.E.; Norton, D.P.; Norton, D.P.; Davenport, T.H. Strategy Maps: Converting Intangible Assets into Tangible Outcomes; Harvard Business Press: Boston, MA, USA, 2004.

77. Kaplan, R.S. Conceptual Foundations of the Balanced Scorecard. Handb. Manag. Account. Res. 2009, 3, 1253-1269.

78. Quezada, L.E.; Cordova, F.M.; Palominos, P.; Godoy, K.; Ross, J. Method for identifying strategic objectives in strategy maps. Int. J. Prod. Econ. 2009, 122, 492-500. [CrossRef]

79. Chiu, M.-C.; Kuo, M.-Y.; Kuo, T.-C. A systematic methodology to develop business model of a product service system. Int. J. Ind. Eng. 2015, 22, 369-381.

80. Anderson, J.C.; Narus, J.A. Capturing the value of supplementary services. Harv. Bus. Rev. 1995, 73, 75-83.

81. Ng, I.C.; Maull, R.; Yip, N. Outcome-based contracts as a driver for systems thinking and service-dominant logic in service science: Evidence from the defence industry. Eur. Manag. J. 2009, 27, 377-387. [CrossRef]

82. Smith, L.; Maull, R.; CL Ng, I. Servitization and operations management: A service dominant-logic approach. Int. J. Oper. Prod. Manag. 2014, 34, 242-269. [CrossRef]

83. Jassbi, J.; Mohamadnejad, F.; Nasrollahzadeh, H. A Fuzzy DEMATEL framework for modeling cause and effect relationships of strategy map. Expert Syst. Appl. 2011, 38, 5967-5973. [CrossRef]

84. Valmohammadi, C.; Sofiyabadi, J. Modeling cause and effect relationships of strategy map using fuzzy DEMATEL and fourth generation of balanced scorecard. Benchmarking Int. J. 2015, 22, 1175-1191. [CrossRef]

85. Saghaei, A.; Ghasemi, R. Using structural equation modeling in causal relationship design for Balanced-Scorecards' strategic map. World Acad. Sci. Eng. Technol. 2009, 49, 1032-1038.

86. Kaplan, R.S.; Norton, D.P. The strategy map: Guide to aligning intangible assets. Strategy Leadersh. 2004, 32, 10-17. [CrossRef]

87. Bustinza, O.F.; Parry, G.C.; Vendrell-Herrero, F. Supply and demand chain management: The effect of adding services to product offerings. Supply Chain Manag. 2013, 18, 618-629. [CrossRef]

88. Lay, G.; Schroeter, M.; Biege, S. Service-based business concepts: A typology for business-to-business markets. Eur. Manag. J. 2009, 27, 442-455. [CrossRef]

89. Baines, T.; Lightfoot, H. Made to Serve: How manufacturers can compete through servitization and product service systems; John Wiley \& Sons: Chichester, WS, UK, 2013.

90. Ulaga, W.; Reinartz, W.J. Hybrid Offerings: How Manufacturing Firms Combine Goods and Services Successfully. J. Mark. 2011, 75, 5-23. [CrossRef] 